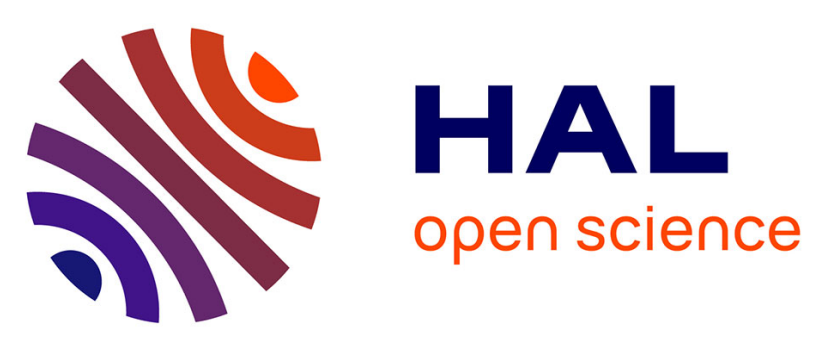

\title{
Dynamic green supplier selection and order allocation with quantity discounts and varying supplier availability
}

Sadeque Hamdan, Ali Cheaitou

\section{To cite this version:}

Sadeque Hamdan, Ali Cheaitou. Dynamic green supplier selection and order allocation with quantity discounts and varying supplier availability. Computers \& Industrial Engineering, 2017, 110, pp.573589. 10.1016/j.cie.2017.03.028 . hal-02023587

\section{HAL Id: hal-02023587 \\ https://hal.science/hal-02023587}

Submitted on 5 Mar 2020

HAL is a multi-disciplinary open access archive for the deposit and dissemination of scientific research documents, whether they are published or not. The documents may come from teaching and research institutions in France or abroad, or from public or private research centers.
L'archive ouverte pluridisciplinaire HAL, est destinée au dépôt et à la diffusion de documents scientifiques de niveau recherche, publiés ou non, émanant des établissements d'enseignement et de recherche français ou étrangers, des laboratoires publics ou privés. 


\title{
Dynamic green supplier selection and order allocation with quantity discounts and varying supplier availability
}

\author{
Sadeque Hamdan, Ali Cheaitou \\ Sustainable Engineering Asset Management (SEAM) Research Group and \\ Industrial Engineering and Engineering Management Department, College of \\ Engineering, University of Sharjah, PO. Box 27272, Sharjah, United Arab \\ Emirates
}

\begin{abstract}
This paper aims to solve a multi-period green supplier selection and order allocation problem with all-unit quantity discounts, in which the availability of suppliers differs from one period to another. The proposed approach involves three stages. In the first stage, decision makers use fuzzy TOPSIS (Technique for Order of Preference by Similarity to Ideal Solution) to assign two preference weights to every potential supplier based on the supplier's performance in two sets of criteria considered separately: traditional and green. In the second stage, top management uses the analytic hierarchy process to assign an importance weight to each of the two sets of criteria based on the organization's strategy. The outputs of the first and second stages serve as inputs for a single-product bi-objective integer linear programming model with deterministic demand that takes into account all-unit quantity discounts and a varying number of suppliers in each period of the planning horizon. We implement the proposed mathematical model in MATLAB R2014a software using the weighted comprehensive criterion method and the branch-and-cut algorithm. Statistical analysis helps determine the most suitable ranking approach for suppliers when their availability changes in each period. This paper presents a numerical comparison between two settings: the first considers all-unit quantity discounts, and the second does not. Moreover, a time study shows that the proposed bi-objective integer linear programming model has an exponential computation time.
\end{abstract}

Keywords: Green supplier selection; Inventory control; Quantity discounts; Supplier availability; Bi-objective optimization; Multi-criteria decision making 


\section{Introduction}

In the current competitive and global environment in which most businesses evolve, one of the most important processes in managing the supply chain of any organization is the selection of its suppliers. This process plays an important role in determining the cost, the quality, and other aspects of the finished product. Therefore, selecting the right suppliers to contract with for procuring physical products or services has become a multicriteria decision-making process. More specifically, to select the best suppliers, organizations must take into account multiple aspects related to these potential suppliers (e.g., price, lead time), to the product (e.g., quality, materials), and more recently to aspects related to the environment and society (e.g., amount of carbon dioxide emitted in production and transportation operations). In addition, national and international regulations as well as international competition are putting more pressure on companies to consider the environmental aspects in the production and delivery of their products and services (Akman, 2015; Hafezalkotob, 2015; Zhang, Wang, \& Ren, 2014). Therefore, taking the environmental aspects into consideration while selecting the right suppliers not only protects the environment but also improves companies' environmental performance and image and helps them achieve environmental goals (Büyüközkan \& Çifçi, 2012; Kannan, Khodaverdi, Olfat, Jafarian, \& Diabat, 2013).

In addition to the decision of selecting suppliers, the procurement process, through which the company allocates orders to the selected suppliers, allows for some economies of scale through the right choice of the quantities to allocate to each supplier. Indeed, the unit price for large orders is usually smaller than the unit price of small orders, even if the orders are made from the same supplier (Taleizadeh, Stojkovska, \& Pentico, 2015). The decrease in the unit price due to the increase in the ordered quantity is known as the quantity discount. Quantity discounts can be part of a pricing strategy and can be a powerful incentive to motivate buyers to increase the amount of their ordered quantities (Mansini, Savelsbergh, \& Tocchella, 2012). The three major types of quantity discounts are incremental quantity discounts, business volume quantity discounts, and all-unit quantity discounts (Ayhan \& Kilic, 2015).

This combined supplier selection and order allocation problem with quantity discounts makes considering a multiple period framework more relevant. On the one hand, a supplier with excellent performance may not be available during the entire planning horizon, due to capacity limitation for example, which creates the need to consider less performing suppliers during some periods of the planning horizon and then to return to the excellent supplier in the following periods. On the other hand, because of the quantity discounts, ordering large quantities from few suppliers may be profitable and therefore requires the consideration of the capacity limitations and the estimation of the inventory holding costs over the entire planning horizon, especially for short life-cycle products.

This paper introduces a single-product, multiple-periods model with deterministic demand in which suppliers are selected and orders are allocated according to cost, traditional criteria, and green criteria. The model allows the available suppliers to vary between the periods of the planning horizon and considers all-unit quantity discounts. The model comprises three stages. In the first stage, decision makers use fuzzy TOPSIS (Technique for Order of Preference by Similarity to Ideal Solution) to calculate two preference weights for each available supplier in each period of the planning horizon based on two sets of criteria taken separately: traditional and green. The set of traditional criteria includes aspects such as cost, quality, and lead time. The set of green criteria includes aspects such as the existence of a supplier's environmental certification and the modes of transportation it uses to deliver the products. The two performance weights of each supplier are calculated on the basis of the historical performance of the supplier or a feasibility study. Fuzzy TOPSIS models the uncertainty or fuzziness of the decision makers' evaluation through the use of Triangular Fuzzy Numbers (TFNs). In the second stage, the highest levels of the organization's hierarchy use the analytic hierarchy process (AHP) to give an importance weight to the traditional criteria as a set and to the green criteria as a set based on the strategic importance of each set in the organization's strategy. The performance weights of each supplier are then combined with the importance weights of the two sets of criteria to produce two final performance weights for each supplier: one traditional and one green. This approach provides the decision maker with flexibility in evaluating the available suppliers, in the sense that a supplier with excellent performance in the traditional criteria and poor performance 
in the green criteria will not rank among the best suppliers if the set of green criteria has a high importance weight. The use of fuzzy TOPSIS is justified because it does not have any inconsistency issues (Lima Junior, Osiro, \& Carpinetti, 2014). Moreover, it allows the model to account for any uncertainty that may arise from the experts while ranking the different alternatives on the basis of the traditional or green criteria, especially when the number of alternatives or criteria is large (Lima Junior et al., 2014). Furthermore, an advantage of using TFNs to model the uncertainty in fuzzy TOPSIS is their facilitating role in the ranking process for the decision makers through the use of linguistic variables. TFNs allow for partial membership, whereas crisp sets allow for either full membership or non-membership. Moreover, using only AHP for both levels (category and criteria) would add more complexity in terms of number of matrices and may result in inconsistent rankings because of the large number of criteria. The use of AHP to calculate the two sets of importance weights is justified because this method is completely consistent when the number of alternatives is equal to two, where the random consistency index becomes equal to zero (Deng, Hu, Deng, \& Mahadevan, 2014). The combined performance weights of the suppliers are then used as inputs for a bi-objective optimization model, which minimizes the fixed and variable costs and maximizes the preference weights of the selected suppliers. The model is solved using the weighted comprehensive criterion method (Dehghani, Esmaeilian, \& Tavakkoli-Moghaddam, 2013).

The rest of this paper proceeds as follows: in Section 2, we provide a detailed literature review on the studied subject. In Section 3, we describe the problem and then provide the model formulation and the solution approach. In Section 4, we compare two ranking approaches, as the available suppliers vary during the periods, and recommend the best approach. We also compare the quantity discount framework with another framework in which no quantity discounts are allowed. Last, we present a study of the computation time to solve the developed bi-objective optimization model. Section 5 concludes the study.

\section{Literature review}

The rich literature on supplier selection without capacity constraints includes the use of approaches such as fuzzy simple multi-attribute rating technique (SMART) (Chou \& Chang, 2008), fuzzy hierarchical TOPSIS (Wang, Cheng, \& Huang, 2009), SMART with fuzzy set theory (Kwong, Ip, \& Chan, 2002), AHP combined with fuzzy set theory (Bruno, Esposito, Genovese, \& Simpson, 2016), and grey system theory with uncertainty theory (Memon, Lee, \& Mari, 2015). In addition, research has examined the case when the capacity of one supplier may not satisfy the entire demand by developing models using different techniques, such as mixed integer programming (Amorim, Curcio, Almada-Lobo, Barbosa-Póvoa, \& Grossmann, 2016; Zhang \& Zhang, 2011), goal programming (Karpak, Kumcu, \& Kasuganti, 1999), Monte Carlo simulation with fuzzy goal programming (Moghaddam, 2015), and fuzzy TOPSIS with mixed integer linear programming (Kilic, 2013).

Recently, some researchers have begun integrating green aspects into the supplier selection and order allocation problem (Freeman \& Chen, 2015; Ghorbani, Bahrami, \& Arabzad, 2012; Hamdan \& Cheaitou, 2015, 2017; Mafakheri, Breton, \& Ghoniem, 2011). Doing so means evaluating suppliers on the basis of product-related criteria, such as the amount of toxic substance, the use of resources, and the use of green technology and environmental labeling (Igarashi, de Boer, \& Fet, 2013). Suppliers can also be evaluated on the basis of organizational-related criteria, such as the environmental management certification, compliance with environmental policies and regulations, staff training on environmental awareness, and the organization's green market share (Igarashi et al., 2013). In particular, research has been conducted in the area of supplier selection and order allocation with quantity discount. For example, Dahel (2003) proposed a multi-objective mixed integer programming model to deal with total business volume discounts in supplier selection and the order allocation problem in multi-item environments. The model is solved using either a preference-oriented approach or the generating approach. Xia and $\mathrm{Wu}$ (2007) proposed a two-stage supplier selection and order allocation model with total business volume discounts. In the first stage, AHP improved by rough set theory is used to assign weights, while in the second stage, a multi-objective, multi-product mixed integer linear programming model is developed to maximize the total weighted quantity of purchasing, to minimize the total purchasing cost, to minimize the number of defective items, and to maximize the number of on-time delivered items. Burke, 
Carrillo, and Vakharia (2008) developed a heuristic to measure the effect of quantity discounts in supplier selection and the order allocation problem for a single item and a single period. They developed three models: the first model considers the linear quantity discount, the second the incremental unit price, and the third the allunit quantity discount. Kokangul and Susuz (2009) addressed the issue of an all-unit quantity discount in a single product multi-criteria environment. They developed a bi-objective non-linear mathematical model that minimizes the total purchasing cost and maximizes the purchasing value obtained using AHP. They solve their model using goal programming. Amid, Ghodsypour, and O'Brien (2009) developed a fuzzy multi-objective mixed integer linear programming model to solve the all-unit quantity discount model for a single product. The model minimizes the total cost, the percentage of rejected items, and the percentage of late delivery items. Lee, Kang, Lai, and Hong (2013) proposed a mixed integer programming model and solved it using a genetic algorithm to minimize the total purchasing cost of a single-item, multi-periods supplier selection problem under all-unit and incremental quantity discounts. Wang and Yang (2009) proposed a two-stage mathematical model to solve an all-unit quantity discount supplier selection problem for a single item in a single-period planning horizon. In the first stage, they perform pair-wise comparison between the criteria using AHP, and in the second stage, the multi-objective mathematical model minimizes total cost, defective rate, and delivery lateness rate. Ebrahim, Razmi, and Haleh (2009) introduced a mathematical model that accounts for three types of quantity discount schemes (all-unit, incremental, and total business volume). The developed model minimizes the cost, late delivered items, and defective items. They introduced a scatter search algorithm to solve the model and compared it with the results obtained using the exact method.

Moreover, Sawik (2010) proposed and compared a single-period multi-objective and a single objective quantity discount model in the supplier selection problem while considering the case of no quantity discount and the case of total business volume and an all-unit quantity discount. Razmi and Maghool (2010) developed a fuzzy biobjective mixed integer multi-item, multi-period supplier selection and an order-sizing model under dynamic demand, capacity, and budget limitations. The proposed model considered different payment methods and price discount policies, such as all-unit discounts, incremental discounts, and total business volume discounts. The first objective function minimizes the total purchasing cost, while the second maximizes the total purchasing value, taking into account the impact of qualitative performance criteria in the purchasing decision. They adopted an augmented $\varepsilon$-constraint and reservation level by Tchebycheff models to solve the bi-objective model. They then obtained the efficiency of each method using an additive utility function offered by the decision maker. Kamali, Fatemi Ghomi, and Jolai (2011) considered the all-unit quantity discount supplier selection problem by developing a multi-objective mathematical model that minimizes the total annual cost, the total number of defective items, and the total number of late delivered items and maximizes the total purchasing value. They solved the model using particle swarm optimization and the scatter search algorithm. Mansini et al. (2012) proposed an integer programming heuristic to solve the supplier selection problem under an all-unit quantity discount and a truckload shipping environment for multiple products.

Furthermore, Zhang and Chen (2013) analyzed the supplier selection problem with quantity discounts under uncertain demand for a single product in a single period by developing a mixed integer non-linear mathematical model solved using the generalized Benders decomposition technique. The proposed model selects suppliers using cost only, without considering any other criteria. Mazdeh, Emadikhiav, and Parsa (2015) proposed a model to solve a single-item supplier selection problem over a multi-period planning horizon. They considered two cases: in the first case, no quantity discounts are allowed, while in the second case, both all-unit quantity and incremental quantity discounts are used. Ayhan and Kilic (2015) developed a two-stage model for multiitem supplier selection and the order allocation problem with an all-unit quantity discount. The model uses fuzzy AHP to obtain weights and mixed integer linear programming to maximize the total purchasing value. Table 1 provides a summary and comparison of the relevant works that deal with the supplier selection with the quantity discount problem. 
Table 1: Literature review summary.

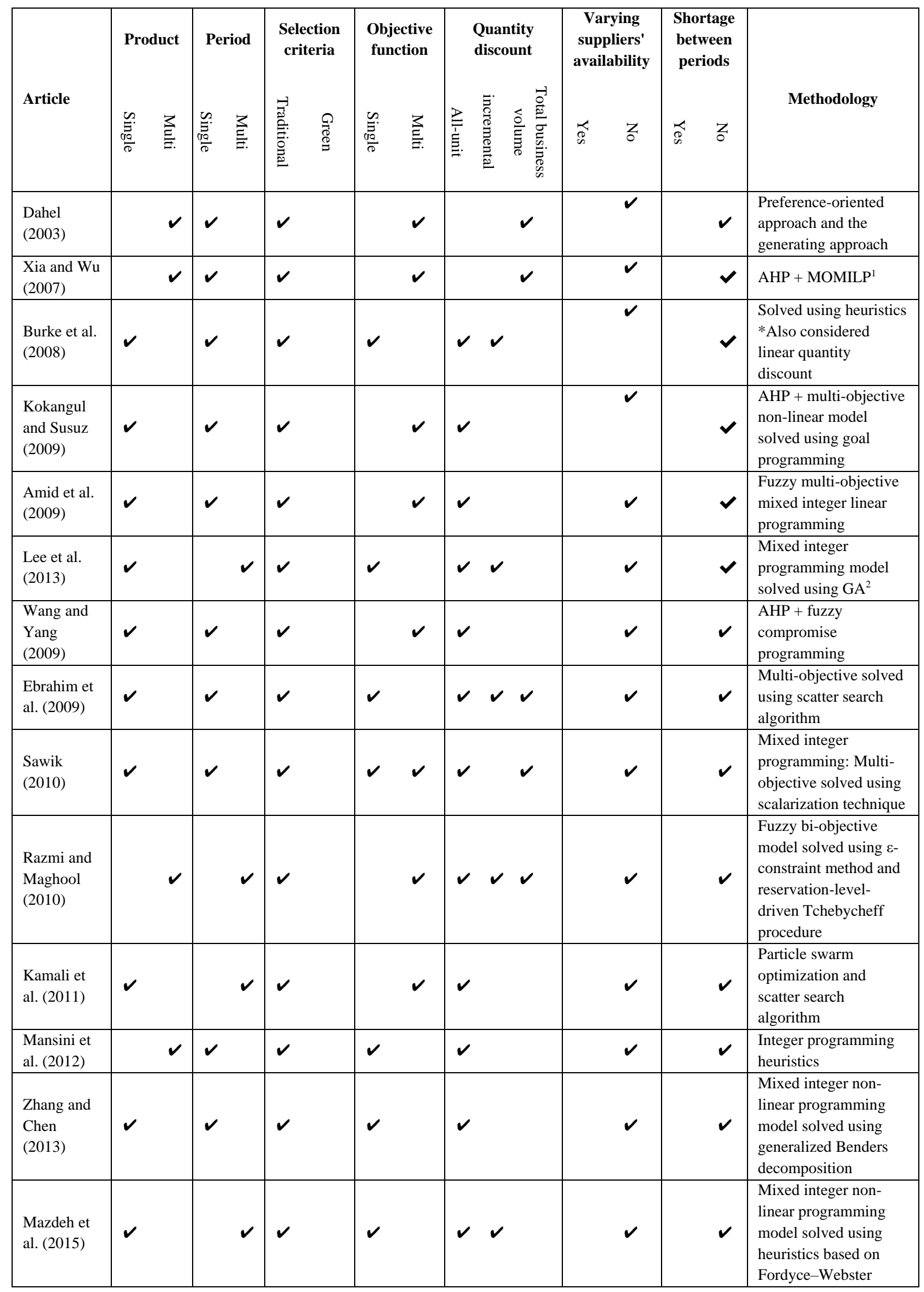

\footnotetext{
${ }^{1}$ Multiple objective mixed integer linear programming

${ }^{2}$ Genetic algorithm
} 


\begin{tabular}{|c|c|c|c|c|c|c|c|c|}
\hline Article & 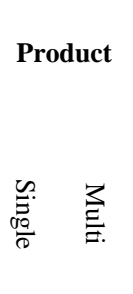 & 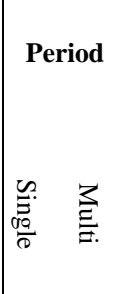 & 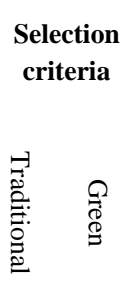 & 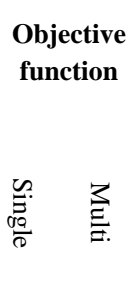 & 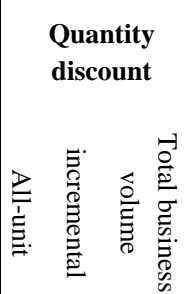 & $\begin{array}{c}\text { Varying } \\
\text { suppliers' } \\
\text { availability }\end{array}$ & 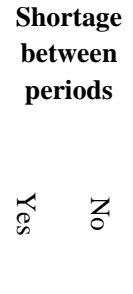 & Methodology \\
\hline & & & & & & & & algorithm \\
\hline $\begin{array}{l}\text { Ayhan and } \\
\text { Kilic } \\
\text { (2015) }\end{array}$ & $v$ & $v$ & $v$ & $v$ & $v$ & $v$ & $v$ & Fuzzy AHP + MILP³ \\
\hline $\begin{array}{l}\text { Hamdan } \\
\text { and } \\
\text { Cheaitou } \\
\text { (2015, } \\
2017)\end{array}$ & $v$ & $v$ & $v$ & $v$ & & $v$ & $v$ & $\begin{array}{l}\text { Fuzzy TOPSIS + AHP } \\
+ \text { + MOMILP } \\
\text { *Fixed number of } \\
\text { suppliers and no } \\
\text { quantity discounts }\end{array}$ \\
\hline This study & $v$ & $\checkmark$ & $v \quad v$ & $v$ & $v$ & 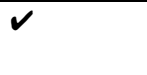 & $v$ & $\begin{array}{l}\text { Fuzzy TOPSIS + AHP } \\
+ \text { + MOMILP }\end{array}$ \\
\hline
\end{tabular}

However, none of the reviewed articles considered the supplier selection and order allocation problem with quantity discounts and green aspects, especially with an emphasis on the set of green criteria on which the suppliers are evaluated. In addition, none of the articles tested the variability in suppliers' availability during the periods of the planning horizon. Finally, most of the articles forced the demand to be satisfied in each period.

Thus, to contribute to the literature, we extend the models that Hamdan and Cheaitou $(2015,2017)$ propose by considering the quantity discounts and the dynamic availability of suppliers. First, the model proposed herein allows decision makers to select their suppliers, plan the procurement of their materials from the selected suppliers, and make related inventory decisions while taking into account the suppliers' green performance in a dynamic way in a multiple-period planning horizon. Indeed, in real life, suppliers have limited capacity, and their ability to supply the required amount of products may change from period to period because, for example, of the change in demand due to seasonality. Therefore, considering this dynamic aspect of suppliers' availability is important. Second, the dynamic suppliers' availability implies the consideration of two possible ways to evaluate suppliers using multi-criteria decision-making tools. This is a distinguishing feature from existing literature that we investigate in this article (see Section 4.1). Third, some suppliers offer quantity discount schemes to their customers. Considering these schemes in the supplier selection and order allocation problem is crucial to account for these incentives, as they may play a determining role in the selection of the suppliers, at least from an economic perspective. Furthermore, considering quantity discounts makes the problem more complex than that in the literature. Fourth, the proposed model considers backlog, and with simple alteration, it can be changed into a lost sales environment. To the best of our knowledge, the studies of Hamdan and Cheaitou $(2015,2017)$ are the only ones to consider this aspect in the green context.

Therefore, considering the dynamic multi-period green supplier selection and order allocation problem, with varying suppliers' availability and an all-unit quantity discount, is relevant from a practical perspective and constitutes a contribution to the literature. This work includes a unique combination of multi-objective mathematical programming and multi-criteria decision-making tools to focus on the aforementioned aspects.

\section{Model}

The model is a single-product, multiple-period bi-objective integer linear programming model that considers allunit quantity discounts and the case when the available suppliers vary during the periods of the planning horizon. The model aims to determine the best suppliers to buy from in each period, the amount that should be ordered from each selected supplier, and the corresponding price ranges so that the total cost of purchasing (TCP) is minimized and the total value of purchasing (TVP) is maximized. We determine the TVP by

\footnotetext{
${ }^{3}$ Mixed integer linear programming
} 
multiplying the combined preference weights (traditional and green) of each supplier by the quantity purchased from that supplier and then by summing up these values. Furthermore, the model determines the inventory level and the amount of the demand that is not satisfied at the end of each period. As mentioned previously, the model consists of three stages: fuzzy TOPSIS, AHP, and bi-objective mathematical optimization model. According to Lima Junior et al. (2014), fuzzy TOPSIS in supplier selection is preferred to fuzzy AHP because of the reversal ranking that occurs in fuzzy AHP when a new alternative or criteria is introduced; this is not the case with fuzzy TOPSIS. Fuzzy TOPSIS involves fewer matrices and does not require any inconsistency checks to justify the selection of fuzzy TOPSIS to rank the suppliers. Moreover, top management uses AHP to determine the importance weights of the two sets of criteria: the traditional criteria and the green criteria. Because a pair-wise comparison is necessary here, we select AHP. Moreover, in this context and because of the number of alternatives (two), AHP does not involve any inconsistencies (Deng et al., 2014).

\subsection{Fuzzy TOPSIS and AHP}

We use fuzzy TOPSIS to determine supplier preference weights based on traditional criteria $\left(T W_{i t}\right)$ and green criteria $\left(G W_{i t}\right)$ separately for each available supplier $i\left(i=1, \ldots, n_{t}\right)$ in each period $t(\mathrm{t}=1, \ldots, \mathrm{T})$ of the planning horizon of length $T$. We adopt Lau et al.'s (2003) five-point linguistic scale (see Table 2; for other different ranking scales, see Chen \& Ku, 2008).

Table 2: Rating scales.

\begin{tabular}{|l|l|l|l|}
\hline \multicolumn{2}{|c|}{ Criterion rating scale } & \multicolumn{2}{c|}{ Alternative rating scale } \\
\hline \multicolumn{1}{|c|}{ Linguistic Variable } & \multicolumn{1}{c|}{ TFN } & Linguistic Variable & \multicolumn{1}{c|}{ TFN } \\
\hline Little importance $(\mathrm{LI})$ & $(0,0,0.25)$ & Very low $(\mathrm{VL})$ & $(0,0,0.25)$ \\
\hline Moderately important $(\mathrm{MI})$ & $(0,0.25,0.50)$ & Low $(\mathrm{L})$ & $(0,0.25,0.50)$ \\
\hline Important $(\mathrm{I})$ & $(0.25,0.50,0.75)$ & Good $(\mathrm{G})$ & $(0.25,0.50,0.75)$ \\
\hline Very important (VI) & $(0.50,0.75,1.00)$ & High $(\mathrm{H})$ & $(0.50,0.75,1.00)$ \\
\hline Absolutely important $(\mathrm{AI})$ & $(0.75,1.0,1.0)$ & Very high $(\mathrm{VH})$ & $(0.75,1.0,1.0)$ \\
\hline
\end{tabular}

The linguistic variables allow decision makers to assign a weight to every criterion in the set of green criteria and to every criterion in the set of traditional criteria. The assignment of the weights is based on the available knowledge and expertise of the decision makers as well as the relative importance of each criterion to the company. Decision makers can assign weights to the suppliers with respect to the criteria using available historical data, the capability studies on the suppliers, and laboratory testing and analysis of the product to be purchased.

Decision makers then use AHP to assign importance weights to the set of traditional criteria $\left(W_{T}^{A H P}\right)$ and to the set of green criteria $\left(W_{G}^{A H P}\right)$. To calculate the supplier preference weights $\left(T W_{i t}\right.$ and $\left.G W_{i t}\right)$ and the set importance weights $\left(W_{T}^{A H P}\right.$ and $\left.W_{G}^{A H P}\right)$, we employ Hamdan and Cheaitou's $(2015,2017)$ methodology.

We separate the green aspects from the traditional aspects in ranking the potential suppliers using fuzzy TOPSIS. This separation results in two preference weights given to each potential supplier, one based on the traditional criteria as a set and one based on the green criteria as a set. Experts from the departments concerned with the purchased item usually perform this step taking into account the past performance of the potential supplier. In the second step, AHP is used, preferably by top management, to assign an importance weight to the set of traditional criteria and another to the set of green criteria based on their relative strategic importance to the organization. This approach is more general and provides more flexibility for decision makers in highlighting the importance of one set over the other (Hamdan \& Cheaitou, 2015, 2017). 


\subsection{Bi-objective integer linear programming model}

The bi-objective optimization model consists of two objective functions. The first aims to maximize the total combined preference weight of the selected suppliers, including their green preference weights and traditional preference weights, while the second aims to minimize the total purchasing cost, the fixed ordering cost, the variable purchasing cost, the inventory holding cost, and the penalty shortage cost. The model takes into consideration all-unit quantity discounts by considering different unit prices for each supplier. Each possible unit price corresponds to a range of possible values for the ordered quantity from the corresponding supplier. For every selected supplier, the model chooses only one unit price and its corresponding range of values for the ordered quantity. The model allows the available suppliers to vary among the different periods of the planning horizon.

\subsubsection{Notations}

\subsubsection{Parameters}

- $\quad T: \quad$ Number of periods in the planning horizon.

- $n_{t}$ : Total number of available suppliers in period $t ; t=1, \ldots, T$.

- $R_{i}$ : Total number of quantity discount ranges (price breaks) for each supplier $i ; i=1, \ldots, n_{t}$.

- $W_{G}^{A H P}$ : Importance weight of the set of green criteria obtained from AHP.

- $W_{T}^{A H P}$ : Importance weight of the set of traditional criteria obtained from AHP.

- $G W_{i t}$ : Preference weight (closeness coefficient) of supplier $i$ in period $t$ based on the green criteria obtained from fuzzy TOPSIS with $i=1, \ldots, n_{t}$ and $t=1, \ldots, T$.

- $\quad T W_{i t}$ : Preference weight (closeness coefficient) of supplier $i$ in period $t$ based on the traditional criteria obtained using fuzzy TOPSIS with $i=1, \ldots, n_{t}$ and $t=1, \ldots, T$.

- $\quad v c_{i r}$ : Unit variable cost for supplier $i, i=1, \ldots, n_{t}$ corresponding to the quantity discount range $r, r=1, \ldots, R_{i}$.

- $\quad F C_{i t}$ : Fixed ordering cost for supplier $i, i=1, \ldots, n_{t}$ in period $\mathrm{t} ; t=1, \ldots, T$.

- $H_{t}$ : Inventory holding cost per unit product in period $\mathrm{t} ; t=1, \ldots, T$.

- $S_{t}$ : Penalty shortage cost per unit product in period $t ; t=1, \ldots, T$.

- $\quad C_{i t r}^{\text {min }}$ : Minimum possible quantity that can be ordered from supplier $i, i=1, \ldots, n_{t}$ if supplier $i$ is selected in period $t, t=1, \ldots, T$ for the quantity-discount range $r, r=1, \ldots, R_{i}$. For $r=1, C_{i t 1}^{\min }$ is the general minimum order quantity of supplier $i$ in period $t$.

- $\quad C_{i t r}^{\max }$ : Maximum possible quantity to be ordered from supplier $i, i=1, \ldots, n_{t}$ if supplier $i$ is selected in period $t, t=1, \ldots, T$ for the quantity-discount range $r, r=1, \ldots, R_{i}$. For $r=R_{i}, C_{i t R_{i}}^{\max }$ represents the maximum supply capacity of supplier $i$ in period $t$.

- $\quad D_{t}$ : Demand in period $t, t=1, \ldots, T, C_{i t R}^{\max }$ is the maximum order quantity.

- $\quad M^{S}, M^{H}$ : Large positive numbers; in this model, we assume that they are equal to the total demand in the planning horizon.

- $\quad S^{S}, S^{H}$ : Small positive numbers that are less than one. In this model, they are equal to 0.5 .

\subsubsection{Decision variables:}

- $Q_{i t r}$ : Quantity to be ordered from supplier $i, i=1, \ldots, n_{t}$ in period $t, t=1, \ldots, T$ within the quantity discount range $r, r=1, \ldots, R_{i}$.

- $Y_{i t r}$ : A binary variable that indicates whether a quantity is ordered from supplier $i, i=1, \ldots, n_{t}$ in period $t, t=1, \ldots, T$ within the quantity discount range $r, r=1, \ldots, R_{i}\left(Y_{i t r}=1\right)$ or not $\left(Y_{i t r}=0\right)$.

\subsubsection{State variables}

- $I_{t}^{H}$ : Available inventory level at the end of period $t, t=1, \ldots, T$. 
- $I_{t}^{S}$ : A negative state variable that indicates the number of unsatisfied demands (shortage) at the end of period $t, t=1, \ldots, T$.

- $Y_{t}^{H}$ : A binary variable that indicates whether the inventory at the end of period $t, t=1, \ldots, T$ is positive $\left(Y_{t}^{H}=1\right)$ or not $\left(Y_{t}^{H}=0\right)$.

- $Y_{t}^{S}$ : A binary variable that indicates whether the inventory at the end of period $t, t=1, \ldots, T$ is negative $\left(Y_{t}^{S}=1\right)$ or not $\left(Y_{t}^{S}=0\right)$.

\subsubsection{Mathematical model}

We define the objective functions as follows:

$\max T V P=T G V P+T T V P$,

with

$$
T G V P=\sum_{t=1}^{T} \sum_{i=1}^{n_{t}} \sum_{r=1}^{R_{i}} W_{G}^{A H P} \times G W_{i t} \times Q_{i t r}
$$

and

$$
T T V P=\sum_{t=1}^{T} \sum_{i=1}^{n_{t}} \sum_{r=1}^{R_{i}} W_{T}^{A H P} \times T W_{i t} \times Q_{i t r}
$$

$\min T C P=\sum_{t=1}^{T} \sum_{i=1}^{n_{t}} \sum_{r=1}^{R_{i}}\left(v c_{i r} \times Q_{i t r}+F C_{i t} \times Y_{i t r}+H_{t} \times I_{t}^{H}-S_{t} * I_{t}^{S}\right)$,

subject to

$$
\begin{aligned}
& Y_{i t r} C_{i t r}^{\min } \leq Q_{i t r} \leq Y_{i t r} C_{i t r}^{\max } \quad \forall i=1, \ldots, n_{t}, \forall t=1, \ldots, T, \quad \forall r=1, \ldots, R_{i}, \\
& I_{t-1}^{H}+I_{t-1}^{S}+\sum_{i=1}^{n_{t}} \sum_{r=1}^{R_{i}} Q_{i t r}-I_{t}^{H}-I_{t}^{S}=D_{t}, \quad \forall t=1, \ldots, T \\
& \sum_{t=1}^{T} \sum_{i=1}^{n_{t}} \sum_{r=1}^{R_{i}} Q_{i t r}+I_{0}=\sum_{t=1}^{T} D_{t}, \\
& Q_{i t r}, I_{t}^{H}, I_{t}^{S} \text { integer, } \quad \forall i=1, \ldots, n_{t}, \forall t=1, \ldots, T, \forall r=1, \ldots, R_{i} \\
& Y_{i t r}, Y_{t}^{H}, Y_{t}^{S} \in\{0,1\}, \quad \forall i=1, \ldots, n_{t}, \forall t=1, \ldots, T, \forall r=1, \ldots, R_{i} \\
& -M^{S} Y_{t}^{S} \leq I_{t}^{S} \leq-S^{S} Y_{t}^{S}, \quad \forall t=1, \ldots, T \\
& S^{H} Y_{t}^{H} \leq I_{t}^{H} \leq M^{H} Y_{t}^{H}, \quad \forall t=1, \ldots, T \\
& Y_{t}^{H}+Y_{t}^{S} \leq 1, \quad \forall t=1, \ldots, T \\
& \sum_{r=1}^{R_{i}} Y_{i t r} \leq 1, \quad \forall i=1, \ldots, n_{t}, \forall t=1, \ldots, T
\end{aligned}
$$

Eq. (1) maximizes the TVP of all suppliers over the planning horizon that consists in the total green value of purchasing (TGVP) and the total traditional value of purchasing (TTVP). It includes the combined weight of every supplier based on the green criteria and the traditional criteria multiplied by the ordered quantities. Eq. (2) 
minimizes the total purchasing cost, which includes the variable cost, the fixed cost, the inventory holding cost, and the penalty shortage cost, over the planning horizon for all the price ranges of all suppliers. Eq. (3) ensures that the ordered quantity from each supplier in each period is within the selected range of quantities for the chosen price. In other words, if the company chooses the price range $r$ of supplier $i$ in period $t$, then constraint (3) ensures that the quantity ordered from supplier $i$ in period $t$ is within the ranges of quantities, $r$, specified by the supplier for the selected price- that is, between $C_{i t r}^{\min }$ and $C_{i t r}^{\max }$. Moreover, $C_{i t 1}^{\min }$ specifies the minimum order quantity that a supplier allows. If the sales management policy of supplier $i$ does not specify a minimum order quantity, then $C_{i t 1}^{\min }=0$, which prohibits ordering negative quantities. Eq. (4) ensures that the demand is satisfied either from the quantity ordered or from the available inventory or is marked as a shortage. Eq. (5) ensures that the total demand for the entire planning horizon is satisfied, even if not necessarily in the same period of occurrence. Eq. (6) ensures the integrality of the decision variables, and Eq. (7) ensures that $Y_{i t r}, Y_{t}^{H}$, and $Y_{t}^{S}$ are binary variables. Eq. (8) ensures that if $I_{t}^{S}$ has a negative value, the corresponding binary variable, $Y_{t}^{S}$, is equal to 1 , and Eq. (9) ensures that if $I_{t}^{H}$ is positive, the corresponding binary variable $Y_{t}^{H}$ is equal to 1 . It is worth noting that the proposed model accounts for shortage and backlog. However, it can easily handle lost sales by setting the value of $M^{S}$ to be equal to zero and by removing constraint (5).

Eq. (10) ensures that at most one inventory type is chosen in each period - in other words, either positive inventory, negative inventory, or neither. Eq. (11) indicates that at most one range is selected from each supplier in each period.

\subsection{Solution approach}

In this paper, we adopt the weighted comprehensive criterion method to solve the bi-objective model because of the simplicity of its implementation and its efficiency in terms of the number of Pareto solutions it can provide (Kamali et al., 2011; Marler \& Arora, 2004). This method is a scalarization approach that uses normalization to allow combining objective functions with different units in one objective function. It first solves the objective functions separately, subject to the original model constraints, to obtain the optimal single objective function values, $T V P_{\max }$ and $T C P_{\min }$. It then combines the two objective functions after multiplying them by a weight in the single objective function problem that aims to minimize the total relative variation of each objective function from its optimal value (Dehghani et al., 2013). We calculate the relative variation (normalization) in Eq. (12) for the maximization problem and in Eq. (13) for the minimization problem:

$f_{1}=\frac{T V P_{\max }-T V P}{T V P_{\max }}$.

$f_{2}=\frac{T C P-T C P_{\min }}{T C P_{\min }}$

We then multiply each relative variation by a relative weight $\left(\alpha_{i}\right)$ and sum up all weighted variations in a single objective function to be minimized:

$\min f=\alpha_{1} f_{1}+\alpha_{2} f_{2}$

Next, we minimize the single objective function (Eq. (14)) subject to the same constraints. Note that changing the values of the weighting parameters $\left(\alpha_{1}\right.$ and $\left.\alpha_{2}\right)$ may lead to different Pareto optimal solutions. In this work, we assume that $\alpha_{1}$ and $\alpha_{2}$ are both equal to 0.5 , except in the determination of Pareto set.

To make the proposed approach easier to use by decision makers in any organization, we developed a simple and user-friendly stand-alone software based on Graphical User Interface using MATLAB R2014a. The software handles the suppliers' ranking step (fuzzy TOPSIS), weights the traditional and green sets of criteria (AHP), and solves the bi-objective optimization model. It uses the MATLAB language and optimization toolbox, which in turn uses the branch-and-cut algorithm. Screenshots of this software showing its features are available in Hamdan and Cheaitou's (n.d.) study. 


\section{Numerical study}

In this section, we present numerical experiments that show the usefulness of the proposed methodology in facilitating the decision-making process for organizations willing to integrate green aspects into their supplier selection process. In Section 4.1, we perform an analysis on the two ranking approaches using fuzzy TOPSIS that can be used in the model. The results from Pareto solutions of the two ranking approaches do not allow us to choose the best method, so we perform statistical analysis for the optimization results using randomly generated input data. The results of the statistical analysis confirm that the difference is not statistical significant. Therefore, because of its simplicity we recommend using the first ranking methods (i.e., ranking the suppliers only once at the beginning of the first period). In Section 4.2, we compare a set of suppliers with quantity discounts with another set of suppliers without quantity discounts but with the same basic characteristics. The results show that the suppliers offering quantity discount schemes are preferred to those without quantity discounts and with comparable prices. Section 4.3 provides a time study on the time required to solve the model under varying problem sizes. This analysis shows the time complexity of the model and that it can be solved for optimality for small to medium-sized instances but may need heuristic solution approaches for large instances.

\subsection{Comparative study on suppliers' ranking}

As we consider that the suppliers' availability changes dynamically from period to period, two possible approaches for ranking the suppliers are possible. In the first approach, all suppliers are ranked one time using fuzzy TOPSIS at the beginning of the planning horizon, even if some suppliers are available during only a few periods of the planning horizon. This ranking compares all the suppliers using fuzzy TOPSIS and uses the resultant ranking for all the periods of the planning horizon. In other words, this approach obtains the traditional preference weight $\left(W_{T}^{A H P} \times T W_{i t}\right)$ and the green preference weight $\left(W_{G}^{A H P} \times G W_{i t}\right)$ of every supplier at the beginning of the planning horizon, taking into account all suppliers even if they are not available in all periods. The second approach ranks, in every period, only the suppliers available in that period by comparing them with each other using fuzzy TOPSIS. In other words, this second approach performs ranking in each period only for the suppliers available in that period and obtains preference weights valid for that period only for each supplier available in each period. In the second approach, the ranking results vary from one period to another depending on the availability of the suppliers in each period.

To better clarify this idea, we use an example with a three-period planning horizon and five potential suppliers: in period one, supplier A and supplier B are available. In period two, supplier A and supplier C are available, and in period three, suppliers B, C, D, E, and F are available. Using the first ranking approach, all suppliers (AF) are ranked on the basis of the traditional and green criteria one time, at the beginning of period one, and the ranking results are used for all three periods. This results in the same weight for supplier B in the first and third periods. Conversely, the second ranking approach ranks the suppliers three times, one time for each period, only for the suppliers available in that period. For example, in period one, only suppliers A and B are ranked, which generates certain preference weights for A and B. For period three, suppliers B, C, D, E, and F are evaluated, which results in preference weights for these five suppliers. The preference weights of supplier B in the first and third periods may therefore be different. This potential difference is due to the normalization step in fuzzy TOPSIS, in which the fuzzy numbers are divided by fuzzy values that vary depending on their nature (benefit or cost) and on the existing suppliers in the ranking process. In summary, the first approach is static and thus is not affected by the changing availability of suppliers, while the second approach is dynamic and takes this changing environment into account. In this section, we compare the two approaches.

\subsubsection{Sample data}

We randomly generated one sample instance of data and tested it using the two ranking approaches over 19 different importance weight scenarios $\left(W_{G}^{A H P}\right.$ and $\left.W_{T}^{A H P}\right)$. Table 3 shows the values of the weights for the 19 scenarios, where $\mathrm{G}$ denotes green and $\mathrm{T}$ denotes traditional, and the numbers next to $\mathrm{G}$ and $\mathrm{T}$ are the values of 
the importance weights of the two sets of criteria. For example, $0.05 \mathrm{G} / 0.95 \mathrm{~T}$ means that $W_{G}^{A H P}=0.05$ and $W_{T}^{A H P}=0.95$.

In the first ranking approach, denoted as case A, we use fuzzy TOPSIS only once, while in the second ranking approach, denoted as case B, we use fuzzy TOPSIS for the available suppliers in each period. The aim is to determine which ranking approach is better and to check whether the difference between the two approaches is significant.

Table 3: Criteria set importance weight scenarios.

\begin{tabular}{|l|l|l|l|}
\hline & Weights & & Weights \\
\hline 1 & $0.05 \mathrm{G} / 0.95 \mathrm{~T}$ & 11 & $0.55 \mathrm{G} / 0.45 \mathrm{~T}$ \\
\hline 2 & $0.1 \mathrm{G} / 0.9 \mathrm{~T}$ & 12 & $0.60 \mathrm{G} / 0.40 \mathrm{~T}$ \\
\hline 3 & $0.15 \mathrm{G} / 0.85 \mathrm{~T}$ & 13 & $0.65 \mathrm{G} / 0.35 \mathrm{~T}$ \\
\hline 4 & $0.2 \mathrm{G} / 0.8 \mathrm{~T}$ & 14 & $0.70 \mathrm{G} / 0.30 \mathrm{~T}$ \\
\hline 5 & $0.25 \mathrm{G} / 0.75 \mathrm{~T}$ & 15 & $0.75 \mathrm{G} / 0.25 \mathrm{~T}$ \\
\hline 6 & $0.3 \mathrm{G} / 0.7 \mathrm{~T}$ & 16 & $0.80 \mathrm{G} / 0.20 \mathrm{~T}$ \\
\hline 7 & $0.35 \mathrm{G} / 0.65 \mathrm{~T}$ & 17 & $0.85 \mathrm{G} / 0.15 \mathrm{~T}$ \\
\hline 8 & $0.40 \mathrm{G} / 0.60 \mathrm{~T}$ & 18 & $0.90 \mathrm{G} / 0.10 \mathrm{~T}$ \\
\hline 9 & $0.45 \mathrm{G} / 0.55 \mathrm{~T}$ & 19 & $0.95 \mathrm{G} / 0.05 \mathrm{~T}$ \\
\hline 10 & $0.50 \mathrm{G} / 0.5 \mathrm{~T}$ & \multicolumn{3}{|c}{} \\
\cline { 1 - 2 } & \multicolumn{4}{|c}{}
\end{tabular}

One decision maker (DM1) evaluates four suppliers (S1, S2, S3, and S4) on the basis of four traditional criteria (TRC1, TRC2, TRC3, and TRC4) and four green criteria (GC1, GC2, GC3, and GC4). Dickson (1966) listed 23 traditional criteria for supplier selection and evaluation, including cost, flexibility, delivery time, quality of product, and payment method. Moreover, the green criteria include environmental labeling, green market share, use of green technology, and environmental management system certification. In the first approach, each criterion and each alternative with respect to each criterion is evaluated using a linguistic variable. These linguistic variables are generated randomly using Microsoft Excel. We then calculate the closeness coefficients (preference weights) of all the suppliers as shown in Table 4.

Table 4: Supplier preference weights using the first approach.

\begin{tabular}{|c|c|c|c|c|c|c|c|c|c|c|c|}
\hline \multicolumn{2}{|l|}{ Criteria } & \multirow{2}{*}{$\begin{array}{l}\text { TRC1 } \\
\text { LI }\end{array}$} & \multirow{2}{*}{$\begin{array}{l}\text { TRC2 } \\
\text { I }\end{array}$} & \multirow{2}{*}{$\begin{array}{l}\text { TRC3 } \\
\text { AI }\end{array}$} & \multirow{2}{*}{$\begin{array}{l}\text { TRC4 } \\
\text { VI }\end{array}$} & \multirow{2}{*}{$\begin{array}{l}\text { GC1 } \\
\text { VI }\end{array}$} & \multirow{2}{*}{$\begin{array}{l}\text { GC2 } \\
\text { LI }\end{array}$} & \multirow{2}{*}{$\begin{array}{l}\text { GC3 } \\
\text { MI }\end{array}$} & \multirow{2}{*}{$\begin{array}{l}\mathrm{GC} 4 \\
\mathrm{I}\end{array}$} & \multicolumn{2}{|c|}{ Preference weights } \\
\hline $\begin{array}{l}\text { Criterion } \\
\text { rating }\end{array}$ & DM1 & & & & & & & & & Traditional & Green \\
\hline \multirow{4}{*}{$\begin{array}{l}\text { Alternative } \\
\text { rating }\end{array}$} & S1 & VL & $\bar{L}$ & $\overline{\mathrm{L}}$ & $\overline{\mathrm{VL}}$ & $\bar{L}$ & $\overline{\mathrm{H}}$ & $\mathrm{VH}$ & $\mathrm{VH}$ & 0.1818 & 0.2987 \\
\hline & S2 & $\bar{G}$ & $\overline{\mathrm{VL}}$ & $\overline{\mathrm{VL}}$ & $\overline{\mathrm{L}}$ & $\mathrm{VH}$ & $\mathrm{L}$ & VL & $G$ & 0.1784 & 0.2917 \\
\hline & S3 & $\mathrm{G}$ & $\mathrm{VH}$ & VL & $\mathrm{L}$ & $\mathrm{H}$ & $\mathrm{H}$ & $\mathrm{G}$ & $\mathrm{VH}$ & 0.273 & 0.3575 \\
\hline & S4 & $\mathrm{VH}$ & $\mathrm{H}$ & VH & $\bar{G}$ & $\bar{G}$ & $\overline{\mathrm{VL}}$ & $\mathrm{L}$ & $\overline{\mathrm{G}}$ & 0.4769 & 0.2405 \\
\hline
\end{tabular}

Note: See Table 2 for definitions of letters.

Table 5 show the availability of the suppliers in each period, where the empty cells represent periods during which the supplier is not available. The second approach repeats the steps of the first approach for every period, taking into account the availability of the suppliers in each period. Table 6 summarizes the obtained preference weights (closeness coefficients) based on the traditional criteria and the green criteria, respectively, for the available suppliers in each period. In Table 6, the crossed cells correspond to periods in which the supplier is not available.

Table 5: Available suppliers in the different periods of the planning horizon.

\begin{tabular}{|c|c|c|c|c|c|c|c|c|c|}
\hline Period & S1 & S2 & S3 & S4 & Period & S1 & S2 & S3 & S4 \\
\hline 1 & $\checkmark$ & $\checkmark$ & & & 11 & $\checkmark$ & & & $\checkmark$ \\
\hline 2 & & $\checkmark$ & $\checkmark$ & $\checkmark$ & 12 & & $\checkmark$ & $\checkmark$ & \\
\hline 3 & $\checkmark$ & $\checkmark$ & & $\checkmark$ & 13 & $\checkmark$ & $\checkmark$ & $\checkmark$ & $\checkmark$ \\
\hline 4 & $\checkmark$ & & & $\checkmark$ & 14 & & $\checkmark$ & $\checkmark$ & $\checkmark$ \\
\hline
\end{tabular}




\begin{tabular}{|c|c|c|c|c|c|c|c|c|c|}
\hline Period & S1 & S2 & S3 & S4 & Period & S1 & S2 & S3 & S4 \\
\hline 5 & $\checkmark$ & & $\checkmark$ & & 15 & $\checkmark$ & $\checkmark$ & $\checkmark$ & $\checkmark$ \\
\hline 6 & & $\checkmark$ & $\checkmark$ & & 16 & $\checkmark$ & $\checkmark$ & $\checkmark$ & \\
\hline 7 & & & $\checkmark$ & $\checkmark$ & 17 & $\checkmark$ & $\checkmark$ & & \\
\hline 8 & $\checkmark$ & $\checkmark$ & $\checkmark$ & & 18 & & & $\checkmark$ & $\checkmark$ \\
\hline 9 & $\checkmark$ & & $\checkmark$ & $\checkmark$ & 19 & $\checkmark$ & & $\checkmark$ & \\
\hline 10 & & $\checkmark$ & $\checkmark$ & $\checkmark$ & 20 & $\checkmark$ & $\checkmark$ & & $\checkmark$ \\
\hline
\end{tabular}

Table 6: Supplier reference weights using the second approach.

\begin{tabular}{|c|c|c|c|c|c|c|c|c|c|c|c|}
\hline & Periods & 1,17 & $2,10,14$ & 3,20 & 4,11 & 5,19 & 6,12 & 7,18 & 8,16 & 9 & 13,15 \\
\hline \multirow{4}{*}{$\begin{array}{l}\text { Preference } \\
\text { weights } \\
\text { based on } \\
\text { traditional } \\
\text { criteria }\end{array}$} & $\mathrm{S} 1$ & 0.3088 & $M$ & 0.1818 & 0.1818 & 0.2665 & & & 0.2665 & 0.1818 & 0.1818 \\
\hline & $\mathrm{S} 2$ & 0.2735 & 0.1784 & 0.1784 & & & 0.3008 & & 0.2533 & & 0.1784 \\
\hline & S3 & & 0.273 & & & 0.3421 & 0.3847 & 0.273 & 0.3421 & 0.273 & 0.273 \\
\hline & $\mathrm{S} 4$ & & 0.4769 & 0.4769 & 0.4769 & & & 0.4769 & 1 & 0.4769 & 0.4769 \\
\hline \multirow{4}{*}{$\begin{array}{l}\text { Preference } \\
\text { weights } \\
\text { based on } \\
\text { green } \\
\text { criteria }\end{array}$} & $\mathrm{S} 1$ & 0.2987 & & 0.2987 & 0.3184 & 0.2987 & & & 0.2987 & 0.2987 & 0.2987 \\
\hline & $\mathrm{S} 2$ & 0.2917 & 0.296 & 0.2917 & & & 0.2965 & & 0.2917 & & 0.2917 \\
\hline & $\mathrm{S} 3$ & & 0.3719 & & & 0.3575 & 0.3719 & 0.3719 & 0.3575 & 0.3575 & 0.3575 \\
\hline & S4 & & 0.2509 & 0.2405 & 0.2731 & & & 0.2509 & & 0.2405 & 0.2405 \\
\hline
\end{tabular}

For the mathematical model, we took the demand and quantity discount price breaks from the work of Lee et al. (2013). Table 7 shows the quantity discount ranges for each supplier. In this numerical example, we assume that the fixed ordering cost is 1000 for each supplier in each period, the inventory holding cost is 4/unit/period, and the unit penalty shortage cost is 10/unit/period.

Table 7: Quantity discounts and price ranges for each supplier.

\begin{tabular}{|c|c|c|c|c|c|c|c|}
\hline & Min Quantity & Max. Quantity & Unit Price & & Min Quantity & Max. Quantity & Unit Price \\
\hline Range & \multicolumn{3}{|c|}{$\mathrm{S} 1$} & Range & \multicolumn{3}{|c|}{ S3 } \\
\hline 1 & 0 & 2000 & 2.99 & 1 & 0 & 900 & 3.05 \\
\hline 2 & 2001 & 3899 & 2.85 & 2 & 901 & 1800 & 2.96 \\
\hline \multirow[t]{2}{*}{3} & 3900 & 9000 & 2.74 & 3 & 1801 & 9000 & 2.83 \\
\hline & \multicolumn{3}{|c|}{ S2 } & & \multicolumn{3}{|c|}{$\mathrm{S} 4$} \\
\hline 1 & 0 & 1100 & 3 & 1 & 0 & 999 & 2.98 \\
\hline 2 & 1101 & 2200 & 2.93 & 2 & 1000 & 2599 & 2.82 \\
\hline 3 & 2201 & 3400 & 2.82 & 3 & 2600 & 4099 & 2.79 \\
\hline 4 & 3401 & 9000 & 2.75 & 4 & 4100 & 9000 & 2.76 \\
\hline
\end{tabular}

\subsubsection{Optimization results}

Table 8 displays the sum of the optimal quantities to order from each supplier in all the periods of the planning horizon and for both cases. The table shows that slight differences (in bold) exist between the optimal solutions of the two ranking approaches. Therefore, to investigate these differences between the two approaches and identify the best approach, we conducted a statistical analysis in the following sections.

Table 8: The sum of the optimal quantities to order from each supplier in all the periods of the planning horizon.

\begin{tabular}{|c|c|c|c|c|c|c|c|c|}
\hline \multirow{2}{*}{ Scenario } & \multicolumn{4}{|c|}{ Case (A) } & \multicolumn{4}{|c|}{ Case (B) } \\
\cline { 2 - 9 } & S1 & S 2 & S 3 & S 4 & S1 & S 2 & S3 & S4 \\
\hline 0.05 G 0.95 T & 1610 & 0 & 4970 & 9110 & 1610 & 0 & 4970 & 9110 \\
\hline 0.1 G 0.9 T & 1610 & 0 & $\mathbf{4 9 7 0}$ & $\mathbf{9 1 1 0}$ & 1610 & 0 & $\mathbf{5 5 7 5}$ & $\mathbf{8 5 0 5}$ \\
\hline 0.15 G 0.85 T & 1610 & 0 & $\mathbf{4 9 7 0}$ & $\mathbf{9 1 1 0}$ & 1610 & 0 & $\mathbf{5 5 7 5}$ & $\mathbf{8 5 0 5}$ \\
\hline 0.2 G 0.8 T & 1610 & 0 & $\mathbf{4 9 7 0}$ & $\mathbf{9 1 1 0}$ & 1610 & 0 & $\mathbf{5 5 7 5}$ & $\mathbf{8 5 0 5}$ \\
\hline 0.25 G 0.75 T & 1610 & 0 & $\mathbf{4 9 7 0}$ & $\mathbf{9 1 1 0}$ & 1610 & 0 & $\mathbf{5 5 7 5}$ & $\mathbf{8 5 0 5}$ \\
\hline 0.3 G 0.7 T & 1610 & 0 & $\mathbf{4 9 7 0}$ & $\mathbf{9 1 1 0}$ & 1610 & 0 & $\mathbf{5 5 7 5}$ & $\mathbf{8 5 0 5}$ \\
\hline 0.35 G 0.65 T & 1610 & 0 & $\mathbf{5 5 7 5}$ & $\mathbf{8 5 0 5}$ & 1610 & 0 & $\mathbf{5 5 7 5}$ & $\mathbf{8 5 0 5}$ \\
\hline
\end{tabular}




\begin{tabular}{|c|c|c|c|c|c|c|c|c|}
\hline 0.40 G $0.60 \mathrm{~T}$ & 1610 & 0 & $\mathbf{5 5 7 5}$ & $\mathbf{8 5 0 5}$ & 1610 & 0 & $\mathbf{5 5 7 5}$ & $\mathbf{8 5 0 5}$ \\
\hline 0.45 G 0.55 T & 1610 & 0 & $\mathbf{5 5 7 5}$ & $\mathbf{8 5 0 5}$ & 1610 & 0 & $\mathbf{5 5 7 5}$ & $\mathbf{8 5 0 5}$ \\
\hline 0.50 G 0.5 T & 1610 & 0 & $\mathbf{5 5 7 5}$ & $\mathbf{8 5 0 5}$ & 1610 & 0 & $\mathbf{5 5 7 5}$ & $\mathbf{8 5 0 5}$ \\
\hline 0.55 G 0.45 T & 1610 & 0 & $\mathbf{5 5 7 5}$ & $\mathbf{8 5 0 5}$ & 1610 & 0 & $\mathbf{5 5 7 5}$ & $\mathbf{8 5 0 5}$ \\
\hline 0.60 G 0.40 T & 1610 & 0 & $\mathbf{5 5 7 5}$ & $\mathbf{8 5 0 5}$ & 1610 & 0 & $\mathbf{5 5 7 5}$ & $\mathbf{8 5 0 5}$ \\
\hline 0.65 G 0.35 T & 1610 & 0 & $\mathbf{7 4 2 5}$ & $\mathbf{6 6 5 5}$ & 1610 & 0 & $\mathbf{9 0 4 5}$ & $\mathbf{8 5 0 5}$ \\
\hline 0.70 G 0.30 T & 1610 & 0 & 12440 & $\mathbf{1 6 4 0}$ & 1610 & 0 & 12440 & $\mathbf{5 0 3 5}$ \\
\hline 0.75 G 0.25 T & 1610 & 0 & 12440 & 1640 & 1610 & 0 & 12440 & 1640 \\
\hline 0.80 G 0.20 T & 1610 & 0 & 12440 & 1640 & 1610 & 0 & 12440 & 1640 \\
\hline 0.85 G 0.15 T & $\mathbf{2 9 3 0}$ & 0 & $\mathbf{1 2 7 6 0}$ & $\mathbf{0}$ & $\mathbf{2 1 2 0}$ & 0 & $\mathbf{1 2 4 4 0}$ & $\mathbf{1 6 4 0}$ \\
\hline 0.90 G 0.10 T & $\mathbf{2 9 3 0}$ & 0 & $\mathbf{1 2 7 6 0}$ & $\mathbf{0}$ & $\mathbf{3 2 5 0}$ & 0 & $\mathbf{1 2 4 4 0}$ & $\mathbf{1 1 3 0}$ \\
\hline 0.95 G 0.05 T & $\mathbf{2 9 3 0}$ & 0 & $\mathbf{1 2 7 6 0}$ & 0 & $\mathbf{3 2 5 0}$ & 0 & $\mathbf{1 2 4 4 0}$ & 0 \\
\hline
\end{tabular}

For more numerical results, we refer the reader to the paper of (Hamdan \& Cheaitou, n.d.) in which Tables A.1 - A.20 show the optimal quantities to be ordered from each supplier in cases A and B for the 19 importance weight scenarios.

\subsubsection{Pareto set for case A}

Table 9: Pareto optimal solutions for both supplier-ranking approaches.

\begin{tabular}{|c|c|c|c|c|c|}
\hline \multicolumn{2}{|c|}{$\begin{array}{l}\text { Objective function } \\
\text { importance weights }\end{array}$} & \multicolumn{2}{|c|}{ Case A } & \multicolumn{2}{|c|}{ Case B } \\
\hline$\alpha_{1}$ & $\alpha_{2}$ & TCP & TVP & TCP & TVP \\
\hline 1 & 0 & 65670.80 & 4404.30 & 65670.80 & 4617.25 \\
\hline 0.95 & 0.05 & 65716.60 & 4670.49 & 65713.40 & 4890.55 \\
\hline 0.9 & 0.1 & 66138.60 & 5072.53 & 65893.25 & 5102.30 \\
\hline 0.85 & 0.15 & 66138.60 & 5072.53 & 66138.60 & 5292.62 \\
\hline 0.8 & 0.2 & 66350.00 & 5152.29 & 66350.00 & 5377.21 \\
\hline 0.75 & 0.25 & 66350.00 & 5152.29 & 66350.00 & 5377.21 \\
\hline 0.7 & 0.3 & 66350.00 & 5152.29 & 66350.00 & 5377.21 \\
\hline 0.65 & 0.35 & 66350.00 & 5152.29 & 66350.00 & 5377.21 \\
\hline 0.6 & 0.4 & 66350.00 & 5152.29 & 66350.00 & 5377.21 \\
\hline 0.55 & 0.45 & 66350.00 & 5152.29 & 66350.00 & 5377.21 \\
\hline 0.5 & 0.5 & 66350.00 & 5152.29 & 66350.00 & 5377.21 \\
\hline 0.45 & 0.55 & 66582.00 & 5169.19 & 66350.00 & 5377.21 \\
\hline 0.4 & 0.6 & 66582.00 & 5169.19 & 66350.00 & 5377.21 \\
\hline 0.35 & 0.65 & 66582.00 & 5169.19 & 66582.00 & 5389.45 \\
\hline 0.3 & 0.7 & 66582.00 & 5169.19 & 66582.00 & 5389.45 \\
\hline 0.25 & 0.75 & 67547.00 & 5196.13 & 67547.00 & 5422.27 \\
\hline 0.2 & 0.8 & 70175.78 & 5258.14 & 67547.00 & 5422.27 \\
\hline 0.15 & 0.85 & 70175.78 & 5258.14 & 71434.08 & 5493.31 \\
\hline 0.1 & 0.9 & 70175.78 & 5258.15 & 71434.08 & 5493.31 \\
\hline 0.05 & 0.95 & 80868.78 & 5344.01 & 88834.68 & 5604.90 \\
\hline
\end{tabular}




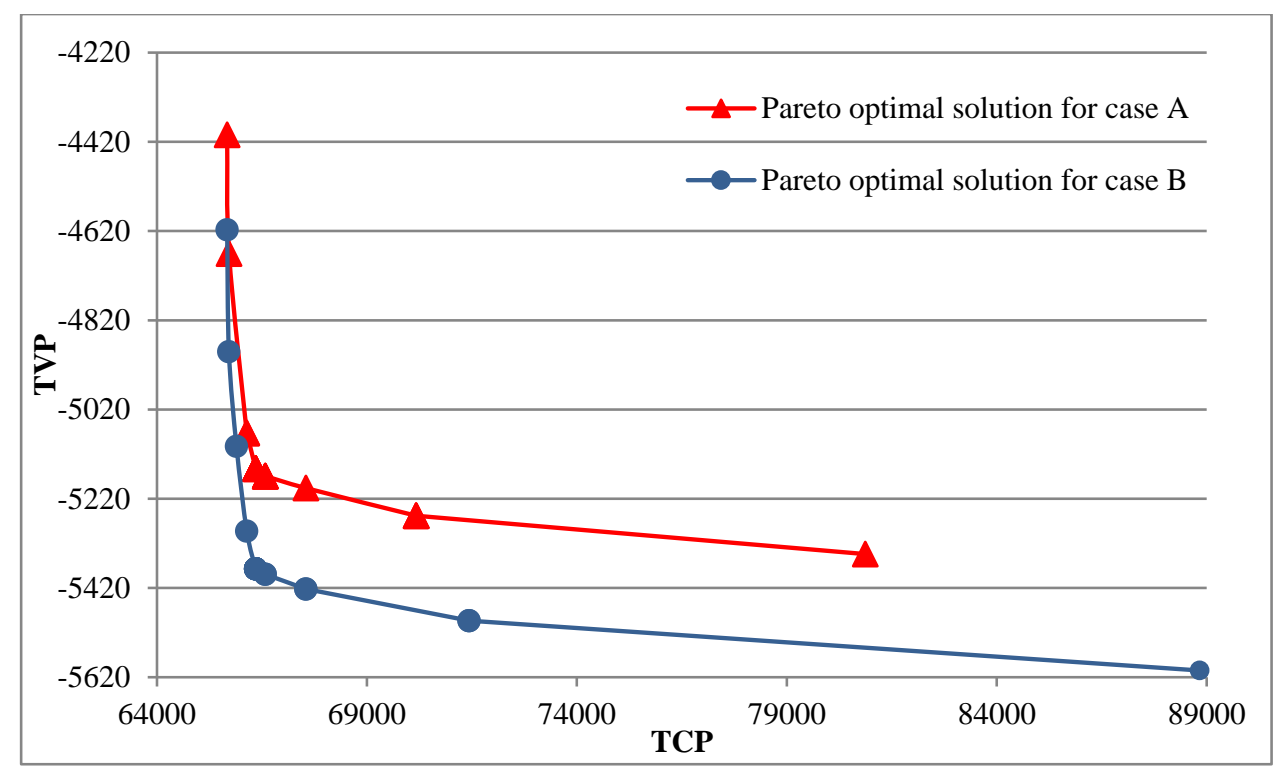

Fig. 1. Pareto frontier for both supplier-ranking approaches.

Table 9 displays optimal solutions obtained for the case of $0.80 \mathrm{G} / 0.20$ T by changing $\alpha_{1}$ and $\alpha_{2}$. Fig. 1 depicts the Pareto set for case A by plotting TCP values versus (-TVP) values. The abscissa axis represents the Pareto optimal TCP for all periods (Eq. (2)), and the ordinate axis represents the Pareto optimal TVP for all periods (Eq. (1)). We obtained these different Pareto solutions by solving the problem defined in Eq. (14), subject to constraints (3)-(11), and by changing the values of $\alpha_{1}$ and $\alpha_{2}$. The used values of the weighting parameters were from 1 to 0.05 for $\alpha_{1}$ and from 0 to 0.95 for $\alpha_{2}$, with increments of 0.05 and -0.05 respectively. For every value of $\left(\alpha_{1} ; \alpha_{2}\right)$, we substituted the obtained optimal solution in (1) and (2) to obtain the corresponding Pareto optimal solution (TCP and TVP values). Fig. 1 shows that an average improvement of the TVP by $2.69 \%$, which corresponds to an average increase in the TGVP (defined in Section 3.2.2) by 4.07\%, can be achieved at an average increase in the cost of $2.82 \%$ using case A, while an average improvement of the TVP by $2.38 \%$, which corresponds to an average increase in the TGVP by $3.61 \%$, can be achieved at an average increase in the cost of $3.48 \%$ using case B. These results do not allow us to draw a general conclusion about the superiority of one of these two ranking approaches, and thus we conduct a more detailed analysis in the following section to compare them using randomly generated input data.

\subsubsection{Statistical analysis}

\subsubsection{Test characteristics}

The proposed model is complex, which makes the use of numerical experiments to analyze the effect of the ranking approaches on the optimal solution challenging. Therefore, we conduct a statistical analysis to test whether there is a significant difference between the two ranking approaches. To our knowledge, the only study that applied hypothesis testing in the field of optimization was that of Hassan et al. (2005), which aimed to compare the genetic algorithm and particle swarm optimization.

We compare the TCP values in case A and case B because they have the same baseline $\left(T C P_{\min }\right)$. At the same time, $T V P_{\max }$ differs between case $\mathrm{A}$ and case $\mathrm{B}$, as this value depends on the suppliers rating (obtained from fuzzy TOPSIS), which differs between the two ranking approaches. As a result, we consider the percentage of variation in the TVP from its optimal value (VTVP) in the statistical comparison to determine whether the difference between case A and case B is statistically significant by generating 16 random samples and testing them on different category weight scenarios of $W_{G}^{A H P}$ and $W_{T}^{A H P}$ at equal objective function importance $\left(\alpha_{1}=\right.$ $\left.\alpha_{2}=0.5\right)$. Table 10 shows the different category weights scenarios. 
Table 10: Different category weights scenarios.

\begin{tabular}{|c|c|c|}
\hline Scenario & $W_{G}^{A H P}$ & $W_{T}^{A H P}$ \\
\hline 1 & 0.1 & 0.9 \\
\hline 2 & 0.4 & 0.6 \\
\hline 3 & 0.6 & 0.4 \\
\hline 4 & 0.9 & 0.1 \\
\hline
\end{tabular}

We randomly generated all the data using the randi ( ) function in MATLAB. This function generates random integers between a minimum and a maximum value, which represents our sample population in this case. The 16 samples were generated using the same minimum and maximum bounds. To generate suppliers' weights for green and traditional criteria, we used Microsoft Excel to randomly select one linguistic variable for each criterion and each supplier, and then we evaluated these linguistic variables using fuzzy TOPSIS for both cases A and B. To perform hypothesis testing, we follow the procedure illustrated in Fig. 2.

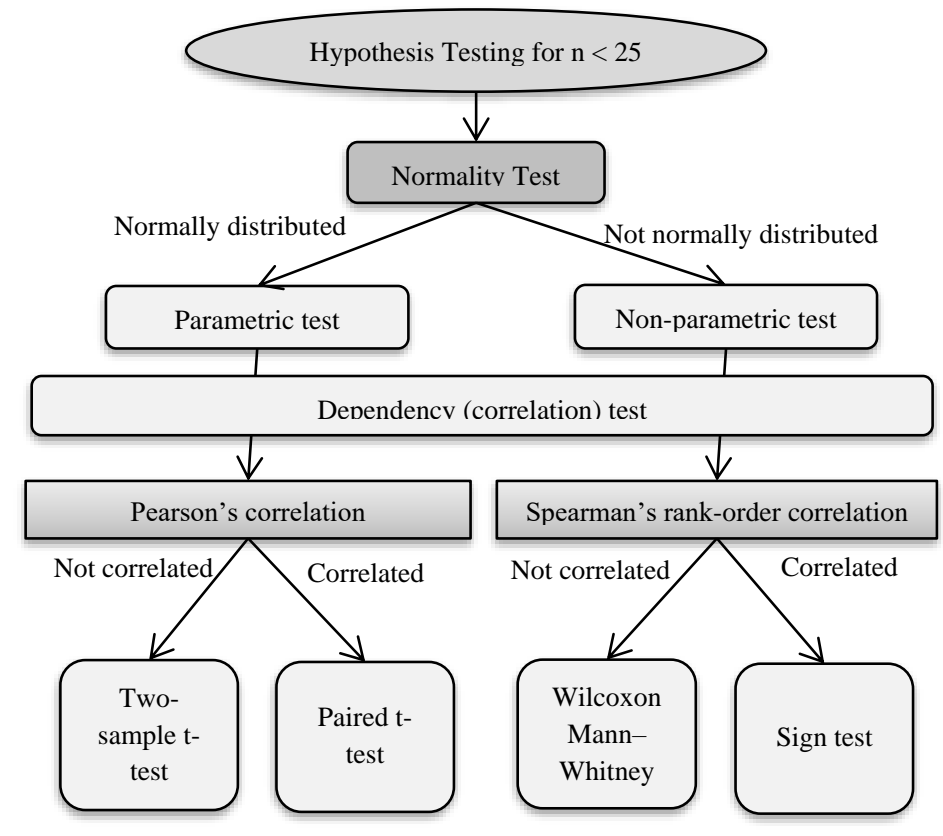

Fig. 2. Hypothesis testing procedure.

\subsubsection{Comparison between the results of case $A$ and case B}

Table 11-Table 14 show TCP and VTVP for the 16 random samples representing the four scenarios of weights mentioned in Table 10.

Table 11: Comparison between TCP and VTVP for case A and case B in scenario 1.

\begin{tabular}{|c|c|c|c|c|}
\hline & TCP Case A & TCP Case B & VTVP Case A & VTVP Case B \\
\hline Sample 1 & 256804.9 & 256806.8 & $0.54 \%$ & $0.53 \%$ \\
\hline Sample 2 & 98512.17 & 98512.17 & $1.50 \%$ & $4.98 \%$ \\
\hline Sample 3 & 418829.1 & 418829.1 & $1.71 \%$ & $1.73 \%$ \\
\hline Sample 4 & 370884.3 & 370884.3 & $0.67 \%$ & $0.71 \%$ \\
\hline Sample 5 & 70994.57 & 70994.57 & $4.55 \%$ & $2.04 \%$ \\
\hline Sample 6 & 115138.7 & 115138.7 & $24.02 \%$ & $24.29 \%$ \\
\hline Sample 7 & 331597.9 & 331597.9 & $1.43 \%$ & $1.26 \%$ \\
\hline Sample 8 & 175141.4 & 175278.1 & $0.31 \%$ & $0.36 \%$ \\
\hline
\end{tabular}




\begin{tabular}{|c|c|c|c|c|}
\hline Sample 9 & 152076.6 & 151378.4 & $0.64 \%$ & $0.94 \%$ \\
\hline Sample 10 & 352614.8 & 352614.8 & $0.19 \%$ & $0.19 \%$ \\
\hline Sample 11 & 373950.3 & 373950.3 & $0.70 \%$ & $0.69 \%$ \\
\hline Sample 12 & 133537 & 134349 & $1.33 \%$ & $1.47 \%$ \\
\hline Sample 13 & 174997.1 & 174997.1 & $1.09 \%$ & $0.24 \%$ \\
\hline Sample 14 & 76207.48 & 76207.48 & $1.40 \%$ & $1.40 \%$ \\
\hline Sample 15 & 382584.6 & 382584.6 & $0.94 \%$ & $0.94 \%$ \\
\hline Sample 16 & 201409.9 & 200850.6 & $2.34 \%$ & $2.80 \%$ \\
\hline Mean & 230330.1 & 230310.9 & 0.027105 & 0.027866 \\
\hline SD & 123079.4 & 123071.6 & 0.057762 & 0.058581 \\
\hline $\begin{array}{c}\text { Coefficient } \\
\text { of variation }\end{array}$ & 0.534361 & 0.534372 & 2.131002 & 2.102204 \\
\hline
\end{tabular}

Table 12: Comparison between TCP and VTVP for case A and case B in scenario 2.

\begin{tabular}{|c|c|c|c|c|}
\hline & TCP Case A & TCP Case B & VTVP Case A & VTVP Case B \\
\hline Sample 1 & 254182.6 & 254182.6 & $3.33 \%$ & $3.17 \%$ \\
\hline Sample 2 & 98512.17 & 98512.17 & $0.00 \%$ & $1.15 \%$ \\
\hline Sample 3 & 411253.8 & 411330.5 & $2.74 \%$ & $2.83 \%$ \\
\hline Sample 4 & 370884.3 & 366735.9 & $0.48 \%$ & $1.86 \%$ \\
\hline Sample 5 & 71058.34 & 71058.34 & $7.96 \%$ & $6.08 \%$ \\
\hline Sample 6 & 115138.7 & 115138.7 & $22.51 \%$ & $22.72 \%$ \\
\hline Sample 7 & 335596.4 & 335596.4 & $0.65 \%$ & $0.55 \%$ \\
\hline Sample 8 & 171667.2 & 169527.5 & $2.69 \%$ & $2.49 \%$ \\
\hline Sample 9 & 152076.6 & 152076.6 & $0.58 \%$ & $0.49 \%$ \\
\hline Sample 10 & 352614.8 & 352614.8 & $0.21 \%$ & $0.20 \%$ \\
\hline Sample 11 & 370880.6 & 370881.9 & $1.85 \%$ & $1.71 \%$ \\
\hline Sample 12 & 133626.9 & 134307.4 & $1.18 \%$ & $0.21 \%$ \\
\hline Sample 13 & 174997.1 & 174997.1 & $1.84 \%$ & $0.81 \%$ \\
\hline Sample 14 & 76339 & 76339 & $0.26 \%$ & $0.26 \%$ \\
\hline Sample 15 & 382584.6 & 382584.6 & $0.86 \%$ & $0.97 \%$ \\
\hline Sample 16 & 201409.9 & 201409.9 & $8.02 \%$ & $7.80 \%$ \\
\hline Mean & 229551.4 & 229205.8 & 0.034472 & 0.033316 \\
\hline SD & 122354.4 & 122079.8 & 0.056579 & 0.056005 \\
\hline $\begin{array}{c}\text { Coefficient } \\
\text { of }\end{array}$ & 0.533015 & 0.532621 & 1.641285 & 1.681025 \\
\hline
\end{tabular}

Table 13: Comparison between TCP and VTVP for case A and case B in scenario 3.

\begin{tabular}{|c|c|c|c|c|}
\hline & TCP Case A & TCP Case B & VTVP Case A & VTVP Case B \\
\hline Sample 1 & 255543.3 & 255543.3 & $4.89 \%$ & $4.83 \%$ \\
\hline Sample 2 & 98512.17 & 98512.17 & $0.01 \%$ & $0.01 \%$ \\
\hline Sample 3 & 415185.1 & 415017.7 & $0.28 \%$ & $0.75 \%$ \\
\hline Sample 4 & 359700.4 & 359369.1 & $3.93 \%$ & $3.28 \%$ \\
\hline Sample 5 & 71642.39 & 71642.39 & $9.14 \%$ & $8.44 \%$ \\
\hline Sample 6 & 115138.7 & 115138.7 & $21.77 \%$ & $21.90 \%$ \\
\hline Sample 7 & 335951 & 335951 & $1.53 \%$ & $1.34 \%$ \\
\hline Sample 8 & 167899.2 & 167602 & $4.61 \%$ & $2.48 \%$ \\
\hline Sample 9 & 152076.6 & 152076.6 & $0.55 \%$ & $0.50 \%$ \\
\hline
\end{tabular}




\begin{tabular}{|c|c|c|c|c|}
\hline Sample 10 & 352863.7 & 352863.7 & $0.08 \%$ & $0.08 \%$ \\
\hline Sample 11 & 373319.8 & 373319.8 & $2.75 \%$ & $2.46 \%$ \\
\hline Sample 12 & 134299 & 134307.4 & $1.11 \%$ & $0.49 \%$ \\
\hline Sample 13 & 174997.1 & 174997.1 & $2.27 \%$ & $1.45 \%$ \\
\hline Sample 14 & 76865.73 & 76865.73 & $0.12 \%$ & $0.12 \%$ \\
\hline Sample 15 & 379997.9 & 379997.9 & $1.02 \%$ & $1.09 \%$ \\
\hline Sample 16 & 201409.9 & 201409.9 & $11.33 \%$ & $11.11 \%$ \\
\hline $\begin{array}{c}\text { Mean } \\
\text { SD }\end{array}$ & 229087.6 & 229038.4 & 0.040869 & 0.037706 \\
\hline $\begin{array}{c}\text { Coefficient } \\
\text { of } \\
\text { variation }\end{array}$ & 0.532303 & 0.532282 & 1.408069 & 1.530105 \\
\hline
\end{tabular}

Table 14: Comparison between TCP and VTVP for case A and case B in scenario 4.

\begin{tabular}{|c|c|c|c|c|}
\hline & TCP Case A & TCP Case B & VTVP Case A & VTVP Case B \\
\hline Sample 1 & 265855.5 & 265855.5 & $2.93 \%$ & $2.90 \%$ \\
\hline Sample 2 & 98534.25 & 98534.25 & $1.13 \%$ & $1.10 \%$ \\
\hline Sample 3 & 417790.5 & 419044.3 & $0.09 \%$ & $0.06 \%$ \\
\hline Sample 4 & 369484.8 & 364371.4 & $0.01 \%$ & $0.04 \%$ \\
\hline Sample 5 & 71642.39 & 76600.95 & $11.73 \%$ & $5.70 \%$ \\
\hline Sample 6 & 115138.7 & 115138.7 & $20.89 \%$ & $20.93 \%$ \\
\hline Sample 7 & 340523 & 340523 & $0.82 \%$ & $0.62 \%$ \\
\hline Sample 8 & 168363 & 167918.3 & $5.40 \%$ & $3.50 \%$ \\
\hline Sample 9 & 152076.6 & 152076.6 & $0.52 \%$ & $0.51 \%$ \\
\hline Sample 10 & 353324 & 352900.6 & $0.00 \%$ & $0.14 \%$ \\
\hline Sample 11 & 375625.2 & 375625.2 & $5.21 \%$ & $4.85 \%$ \\
\hline Sample 12 & 134860.3 & 134299 & $1.48 \%$ & $1.57 \%$ \\
\hline Sample 13 & 174997.1 & 174997.1 & $2.85 \%$ & $2.31 \%$ \\
\hline Sample 14 & 76964.99 & 76964.99 & $1.28 \%$ & $1.28 \%$ \\
\hline Sample 15 & 384937.5 & 386374.7 & $0.19 \%$ & $0.11 \%$ \\
\hline Sample 16 & 226733.3 & 226733.3 & $0.21 \%$ & $0.20 \%$ \\
\hline Mean & 232928.2 & 232997.4 & 0.034215 & 0.028639 \\
\hline SD & 123676.5 & 123143.1 & 0.05573 & 0.051296 \\
\hline Coefficient & 0.530964 & 0.528517 & 1.628821 & 1.79114 \\
\hline variation & & & & \\
\hline
\end{tabular}

\subsubsection{Normality checks}

We apply a normality check to determine the type of test because we generate the input data randomly and perform the test on the solution of the optimization model after solving the problem using the two ranking approaches. We used Minitab software to check the normality assumption of the data by comparing the p-values with a significance level of $\alpha=0.05$. The results show that the samples of the TCP values are normally distributed (see Fig. 3); however, the difference in TCP values for case A and case B is not normally distributed (see Fig. 4), which means that a non-parametric test must be used. The normality assumption is violated for the VTVP for case A and case B and the difference in VTVP of case A and case B (VTVP A-B), as we show in Fig. 5 and Fig. 6, respectively. 


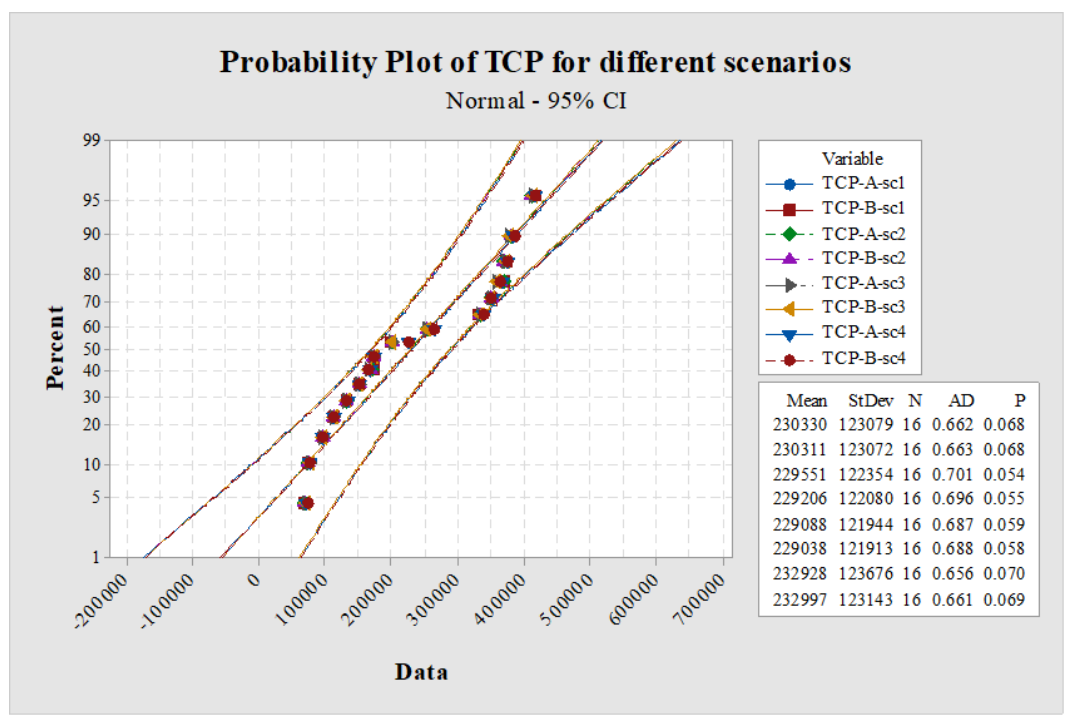

Fig. 3. Normality check for TCP in case A and case $B$ in all scenarios.

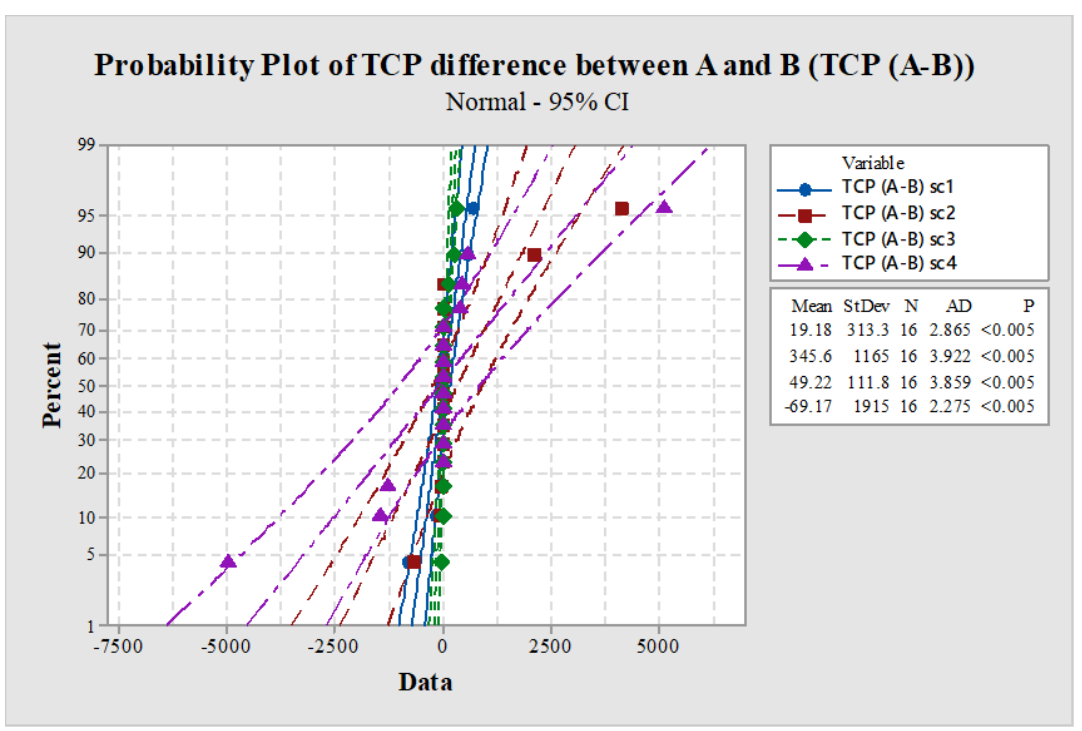

Fig. 4. Normality check for difference in TCP between case A and case B in all scenarios.

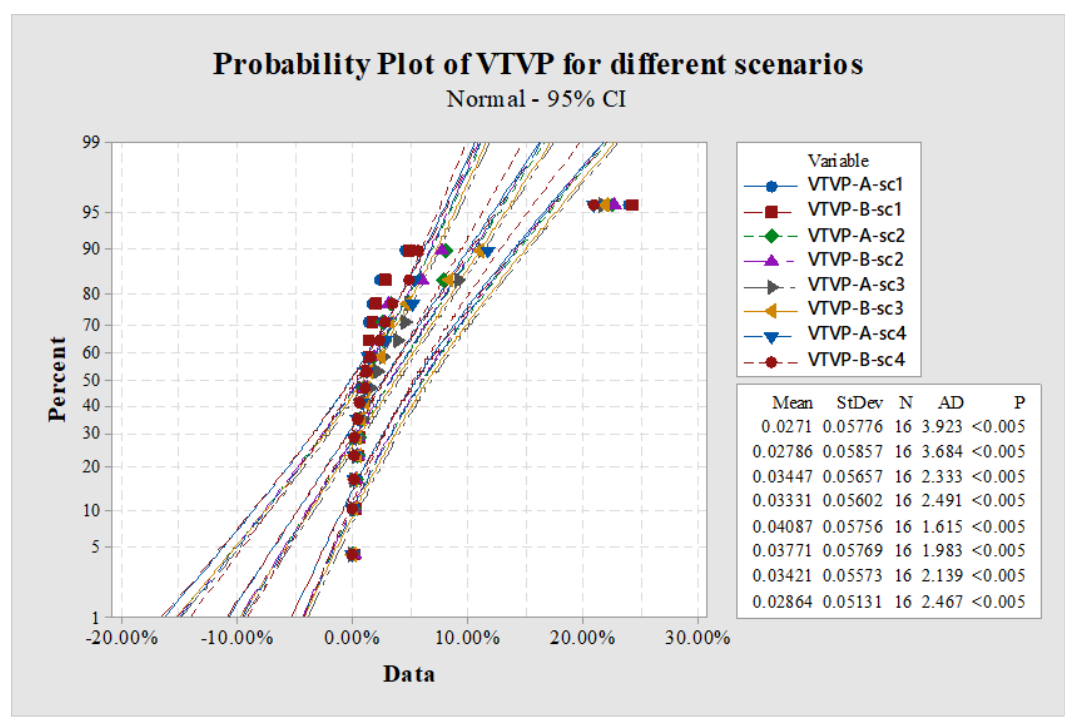


Fig. 5. Normality check for VTVP in case A and case $B$ in all scenarios.

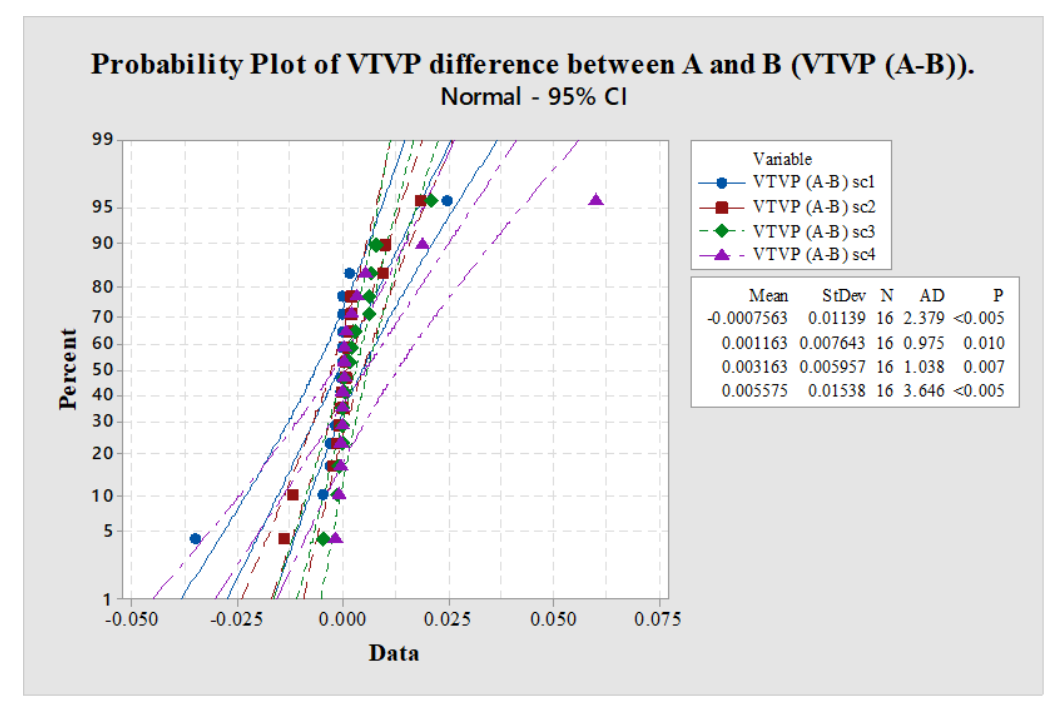

Fig. 6. Normality check for difference in VTVP between case A and case B in all scenarios.

\subsubsection{Spearman rank-order correlation check}

As indicated previously, the normality assumption is violated, and therefore we use the Spearman's rank-order correlation test. The Spearman's rank-order correlation coefficient can be calculated with Minitab software. We test the following hypotheses about the correlation tested at the 5\% significance level:

- $\quad H_{0}^{a}: \rho=0$, which means that no correlation exists.

- $\quad H_{1}^{a}: \rho \neq 0$, which means that a correlation does exist.

We calculated the Spearman correlation coefficient using Minitab software and found it to be approximately equal to 1 in all scenarios of TCP; for the VTVP, we found it be $0.890,0.803,0.976$, and 0.979 for scenarios 1 , 2,3 , and 4 , respectively. The corresponding p-values are 0.00 for all scenarios in both TCP and VTCP. From these results, we can conclude that there is a correlation between the two samples (case A and case B) in the TCP and VTVP in all scenarios, and therefore we carry out the "sign test".

\subsubsection{Hypothesis test}

We test the hypotheses at the 5\% significance level. The sign test checks the following hypotheses for the percentage difference in the TCP:

- $\quad H_{0}^{b}: \tilde{\mu}_{D}=0$, which means that the difference between the medians of case $\mathrm{A}$ and case $\mathrm{B}$ is equal to zero.

- $\quad H_{1}^{b}: \tilde{\mu}_{D} \neq 0$, which means that the difference between the medians of case $\mathrm{A}$ and case $\mathrm{B}$ is not equal to zero.

We derive the results shown in Table 15 from the sign test using Minitab software for all scenarios for both TCP and VTVP. According to the statistical analysis, the 16 random samples showed no significant differences in TCP or VTVP when using the case A or case B ranking approach.

Table 15: Hypotheses test results.

\begin{tabular}{|c|c|c|c|c|c|}
\hline TCP & p-Value & Decision & VTVP & p-Value & Decision \\
\hline Scenario 1 & 1.000 & \multirow{4}{*}{$\begin{array}{c}\text { No } \\
\text { significant } \\
\text { difference }\end{array}$} & Scenario 1 & 0.5811 & \multirow{4}{*}{$\begin{array}{c}\text { No } \\
\text { significant } \\
\text { difference }\end{array}$} \\
\hline Scenario 2 & 1.000 & & Scenario 2 & 0.3018 & \\
\hline Scenario 3 & 0.625 & & Scenario 3 & 0.0923 & \\
\hline Scenario 4 & 1.000 & & Scenario 4 & 0.1185 & \\
\hline
\end{tabular}




\subsubsection{Findings}

From the comparison of the two ranking approaches, we found that both result in close TCP and VTVP mean values, as displayed in Table 11-Table 14. In addition, the statistical analysis confirmed that the difference is not statistically significant. As a result, both supplier ranking approaches can be used; however, the second ranking approach (case B) requires ranking the suppliers for every period, which means more time and effort. Therefore, as the model also accounts for planning decisions, decision makers should rank all suppliers in the planning horizon once at the beginning of the planning horizon (case A).

\subsection{Comparison between the suppliers with and without quantity discounts}

\subsubsection{Numerical example}

The goal of this section is to investigate the case when a supplier offers all-unit quantity discounts, and a competing supplier with the same characteristics charges the same unit price regardless of the ordered quantity. We use the data of case A presented in section 4.1.1 as the base case and analyze them over the 19 importance weight scenarios shown in Table 3 . The total quantity ordered from each supplier in all the periods serves as the basis of the comparison. In addition to the four suppliers (S1, S2, S3, and S4) of case A, we add four new suppliers (S5, S6, S7, and S8) as competitors of the four original suppliers. Every new supplier competes with one original supplier. The new suppliers do not offer quantity discounts and therefore charge the same unit price regardless of the ordered quantity. We calculate this unit price of every new supplier as the average of the maximum unit price and minimum unit price of the original suppliers, as shown in Fig. 7.

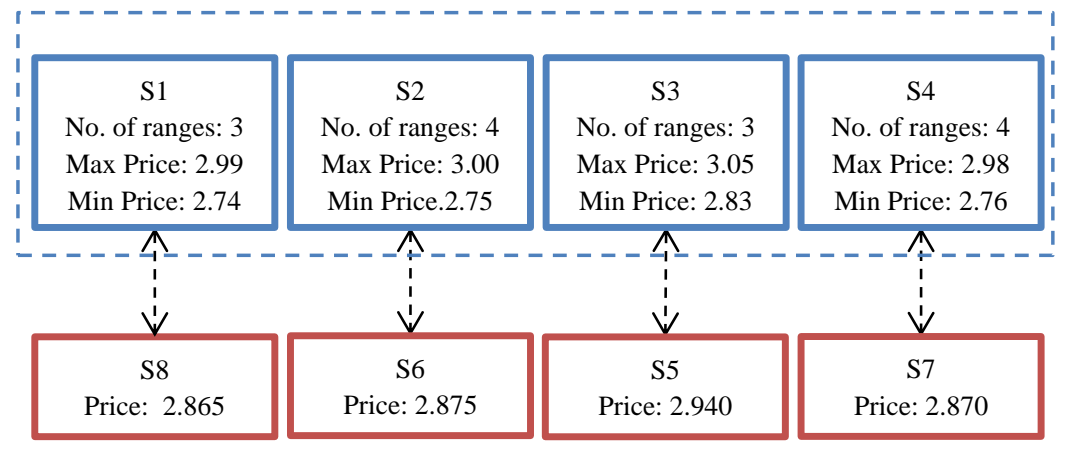

Fig. 7. List of suppliers with and without quantity discount and their characteristics.

\subsubsection{Analysis of the results}

We add supplier S5 first to the original suppliers (S1, S2, S3, and S4) and solve the problem defined in Eqs. (14) and (3)-(11) for the 19 importance weight scenarios. Then, we add supplier S6, while keeping supplier S5 as an available supplier, and solve the same optimization problem again for the same 19 scenarios. Finally, we introduce supplier S7 while keeping S5 and S6 and then supplier S8 while keeping the other seven suppliers. When S5 entered the selection process, the total quantities ordered from S3 marked a decrease that ranged from $51.51 \%$ to $65.76 \%$. The introduction of S6, which has similar characteristics to S2, resulted in a reduction in the optimal quantity ordered from S1 by $65 \%$ to $100 \%$. This reduction depends on the importance weights. The introduction of $\mathrm{S} 7$ as a potential supplier caused a reduction of between $51 \%$ and $100 \%$ in the optimal quantity ordered from S4. On the introduction of S8, it outperformed S6 in terms of ordered quantity. To better understand these results, we plot the quantity discount ranges of every supplier against the price of the competing supplier in Fig. 8. 
(a) Price range for $\mathrm{S3}$ and $\mathrm{S5}$

\begin{tabular}{l|l|l|l|l|} 
& \multicolumn{3}{c}{90} & \multicolumn{2}{c}{1800} & \\
S3 & $\mathbf{3 . 0 0}$ & & $\mathbf{2 . 9 6}$ & $\mathbf{2 . 8 2}$ \\
\cline { 2 - 5 } S5 & \multicolumn{3}{|c|}{2.94} & $\mathbf{2 . 9 4}$ \\
\cline { 2 - 5 } & & &
\end{tabular}

(b) Price range for S2 and S6

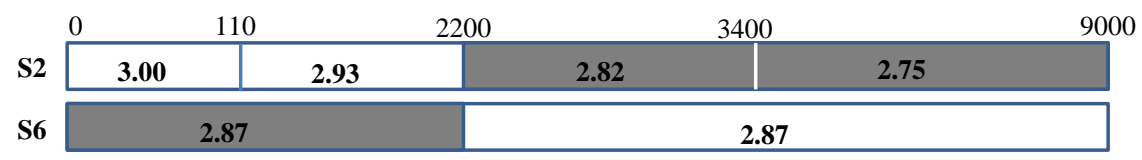

(c) Price range for $\mathrm{S} 1$ and $\mathrm{S6}$

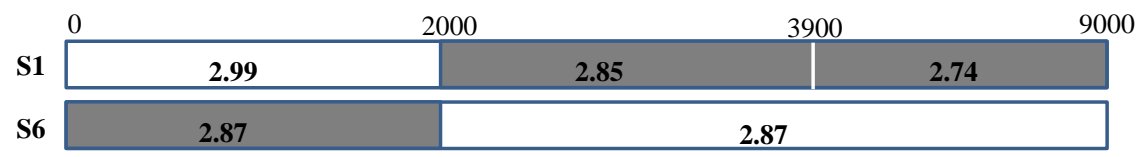

Fig. 8. Comparison of the quantity discount ranges.

Fig. 8 (a) confirms that any quantity that is fewer than 1800 units and ordered from S3 in case A will be ordered from S5, which has the same characteristics as S3 but a unit price of 2.94. To verify this, we provide quantities ordered from $\mathrm{S} 3$ in each period of the scenario $(0.75 \mathrm{G} / 0.25 \mathrm{~T})$ in Table 16 . In the original scenario (case A), the quantities ordered from S3 vary between 465 in period 6 and 2410 in period 8; however, when S5 is considered, only quantities greater than 1800 units are ordered from S3.

Table 16. Optimal quantities ordered in case $A$ and in the case with S5 from S3 and S5.

\begin{tabular}{|c|c|c|c|c|c|c|c|c|c|c|c|c|c|c|}
\hline & Period & 2 & 5 & 6 & 7 & 8 & 9 & 10 & 12 & 13 & 15 & 16 & 18 & 19 \\
\hline $\begin{array}{c}\text { Original } \\
\text { Case } \\
\text { (Case A) } \\
\end{array}$ & S3 & 720 & 725 & 465 & 1510 & 2410 & 515 & 1850 & 540 & 840 & 780 & 830 & 650 & 605 \\
\hline \multirow{2}{*}{$\begin{array}{c}\text { Case } \\
\text { with S5 }\end{array}$} & $\mathrm{S} 3$ & 0 & 0 & 0 & 0 & 2410 & 0 & 1850 & 0 & 0 & 0 & 0 & 0 & 0 \\
\hline & S5 & 720 & 725 & 465 & 1510 & 0 & 515 & 0 & 540 & 840 & 780 & 830 & 650 & 605 \\
\hline
\end{tabular}

When we add S6 to the selection process, it competes with S1 instead of S2. Indeed, in case A, no order was made from S2; therefore, S6 does not compete with any other suppliers. However, because the performance weights of S1 and S2 are close (0.1818 and 0.1784 in the traditional criteria and 0.2987 and 0.2917 in the green criteria for S1 and S2, respectively), S6 replaces S2 in all the orders having a quantity of fewer than 2200 units and replaces S1 in all the orders having a quantity of fewer than 2000 units, as shown in Fig. 8 (b).

Table 17 shows the quantities ordered from S1 without and with S6 in the scenario $(0.75 \mathrm{G} / 0.25 \mathrm{~T})$. However, in some scenarios, such as $(0.95 \mathrm{G} / 0.05 \mathrm{~T})$, not all quantities fewer than 2000 units and ordered from S1 in case A were shifted to S6, as shown in

Table 18. This result is caused by the difference between the green weights of the two suppliers. The difference is significant because the green set of criteria is given a much higher importance weight than the traditional set. This result confirms the importance of separating the green criteria from the traditional criteria, because this separation gives the decision makers a degree of flexibility and allows them to focus on one category of criteria more than the other category, in the supplier selection process, by assigning a higher importance weight.

Table 17: Optimal quantities ordered in case A vs. the case with S5 and S6 in 0.75 G/0.25 T scenario.

\begin{tabular}{|c|c|c|c|}
\hline Case & Supplier & Period 1 & Period 17 \\
\hline \multirow{2}{*}{ Case A } & S1 & 660 & 950 \\
\cline { 2 - 4 } & S6 & 0 & 0 \\
\hline \multirow{2}{*}{ Case with S5 and S6 } & S1 & 0 & 0 \\
\cline { 2 - 4 } & S6 & 660 & 950 \\
\hline
\end{tabular}


Table 18: Optimal quantities ordered in case A vs. the case with S5 and S6 in 0.95 G/0.05 T scenario.

\begin{tabular}{|c|c|c|c|c|c|c|}
\hline Case & Supplier & Period 1 & Period 3 & Period 4 & Period 11 & Period 17 \\
\hline \multirow{2}{*}{ Case A } & S1 & 660 & 510 & 810 & 320 & 950 \\
\cline { 2 - 8 } & S6 & 0 & 0 & 0 & 0 & 0 \\
\hline \multirow{2}{*}{ Case with S5 and S6 } & S1 & 0 & 0 & 810 & 320 & 0 \\
\cline { 2 - 8 } & S6 & 660 & 510 & 0 & 0 & 950 \\
\hline
\end{tabular}

For more detailed numerical results, we refer the reader to (Hamdan \& Cheaitou, n.d.), where Tables B.1 - B.5 show the sum of the optimal quantities ordered from each supplier in all periods of the planning horizon for the different importance weight scenarios.

\subsubsection{Findings}

We compare suppliers that provide quantity discounts with suppliers that do not but have other similar characteristics. Depending on the quantity to be purchased, a supplier offering quantity discounts has a better chance of being selected at large quantities when its unit price is lower than the supplier with similar characteristic but without quantity discount and offering an average unit price.

\subsection{Computation time analysis for the bi-objective model}

\subsubsection{Computer specifications and computation time fitting}

In this section, we assess the total computation time required to solve the three optimization problems of the biobjective integer linear programming model defined in Section 3.3 and in Eq. (14). Previously, we solved all the optimization models using the branch-and-cut algorithm implemented in the optimization toolbox of MATLAB R2014a. We ran the models on a computer equipped with an Intel(R) Core(TM) i7-3610 QM, CPU @ $2.3 \mathrm{GHz}$ $2.3 \mathrm{GHZ}$ and an $8.00 \mathrm{~GB}$ RAM and Microsoft Windows 7 64-bit operating system.

We now change the problem size to investigate the effect on the computation time of the number of suppliers, the number of periods, and the number of quantity discount ranges for each supplier. Ninety problems were solved for this purpose. The input data required that the problems be generated randomly using the (RANDBETWEEN) function of Microsoft Excel. The corresponding problems were solved and their computational time was recorded. We refer the reader to (Hamdan \& Cheaitou, n.d.) for more details about the raw data.

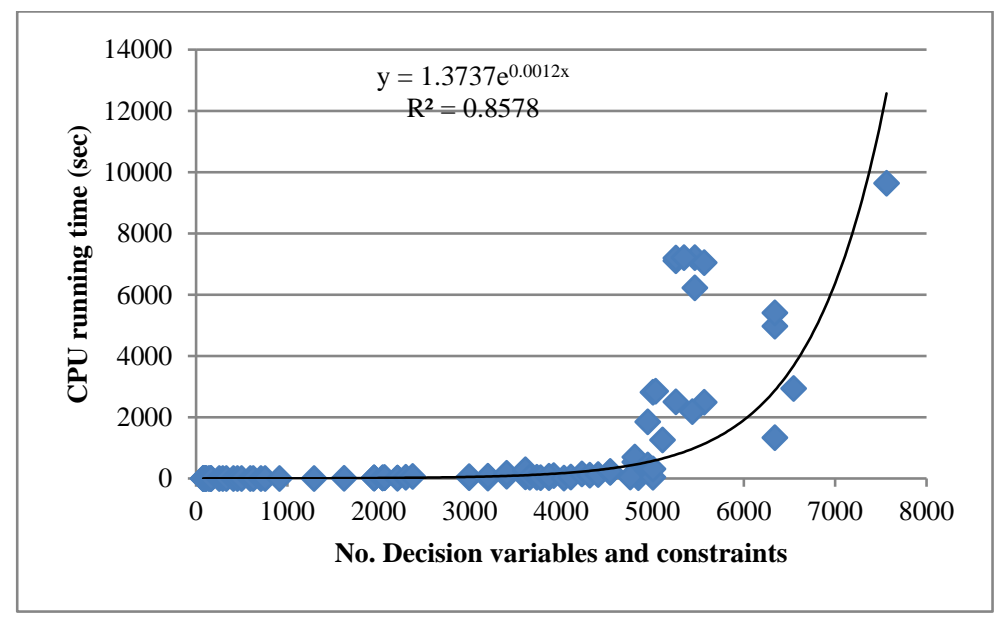

Fig. 9. Number of decision variables and constraints versus the CPU running time (exponential fitting).

We add the number of decision variables and constraints together. Fig. 9 displays the CPU running time as a function of the total number of decision variables and constraints and shows that the computation time can be 
fitted as an exponential function with a coefficient of determination $\left(R^{2}=86 \%\right)$, which means that the obtained regression model accounts for $86 \%$ of the variability in the data.

\subsubsection{Big O notation}

The big O notation can help classify a model or an algorithm in terms of the required processing time to solve the model or execute the algorithm as the input size changes. A description of a function in terms of the big $\mathrm{O}$ notation usually provides an upper bound on the growth rate of the function (Leiserson, Rivest, Stein, \& Cormen, 2009). The formal definition of the big O notation is as follows:

$T(n)=O(g(n))$

if and only if there are two constants $c$ and $n_{0}>0$, such that $T(n) \leq c \times g(n)$ for all $n \geq n_{0}$, where $n$ is the problem size, $g(n)$ is the function that corresponds to the upper bound on the growth rate of the function $T(n)$, and $T(n)$ is the time function for the algorithm.

The big $\mathrm{O}$ notation is based on two assumptions: the input argument, $n$, is restricted to be a non-negative integer and the value of $T(n)$ is non-negative for all values of $n$. As Fig. 9 shows, the computation time function is exponential and leads to the following Lemma:

Lemma 1: As a function of the number of decision variables and constraints, $n$, the computation time, $T(n)$, required to optimize the bi-objective ILP problem described in Section 3.3.2 using the branch-and-cut algorithm has an exponential upper bound function: $T(n)=O\left(e^{n}\right)$.

Proof 1: For the best-fitting curve function in Fig. 9, we consider $T(n)=1.4588 e^{0.0038} n \leq c e^{n}$. Assuming $n_{0}=1$, the goal is to find the value for $\mathrm{c}$, such that $c e^{n}$ represents the upper bound of the time function, $T(n) \leq c e^{n}$, which leads to

$$
\frac{1.4588 e^{0.0038 n}}{e^{n}} \leq c, \text { for } n_{0}=1
$$

and consequently, for $n_{0}=1$, we get $c \geq 0.5387$. Therefore, $T(n)$ is $O\left(e^{n}\right)$ for all $n \geq n_{0}=1$, and $c=$ 0.5387. This completes the proof.

\subsubsection{Findings}

The bi-objective model formulated has an exponential computation time function of $T(n)=O\left(e^{2}\right)$. This result indicates that the model can be solved in a reasonable computational time for small and medium-sized problems while a heuristic approach is required for large problems.

\section{Conclusion}

In this paper, we proposed a supplier selection and order allocation model that takes into account all-unit quantity discounts and variable availability of suppliers. The model consists of three stages: fuzzy TOPSIS, AHP, and a bi-objective integer linear programming model. We solve the model using the weighted comprehensive criterion method and the branch-and-cut algorithm by implementing it in MATLAB R2014a. Moreover, we conduct a numerical analysis to analyze three aspects of the model: the suppliers' ranking, the quantity discounts, and the computation time. As the proposed model accounts for the variability in the suppliers' availability from one period to another, an analysis to determine whether to rank all the suppliers only once at the beginning of the planning horizon or to rank the available suppliers in each period is relevant. It is also relevant to compare suppliers that offer quantity discounts with those with fixed unit prices. The results of the numerical study confirm that applying fuzzy TOPSIS once for all the suppliers at the beginning of the planning horizon and using the results for all periods does not differ significantly than when applying fuzzy TOPSIS in each period. Moreover, ranking the suppliers in every period wastes more time and effort than ranking all the suppliers only once; therefore, the approach of ranking all suppliers once at the beginning of the 
planning horizon should be considered. For the second aspect of the numerical application, we tested the model on the case when a supplier with no quantity discounts was introduced into the system. We assumed that the suppliers with and without quantity discounts have the same characteristics. Finally, the time analysis results revealed that the model has an exponential time function with $O\left(e^{n}\right)$, which means that the time will increase exponentially as the problem size increases. Avenues for future research include considering stochastic demand, taking into account probabilistic suppliers' availability, and developing heuristic approaches for solving large size instances of the considered problem.

\section{References}

Akman, G. (2015). Evaluating suppliers to include green supplier development programs via fuzzy c-means and VIKOR methods. Computers and Industrial Engineering, 86, 69-82. http://doi.org/10.1016/j.cie.2014.10.013

Amid, A., Ghodsypour, S. H., \& O’Brien, C. (2009). A weighted additive fuzzy multiobjective model for the supplier selection problem under price breaks in a supply Chain. International Journal of Production Economics, 121(2), 323-332. http://doi.org/10.1016/j.ijpe.2007.02.040

Amorim, P., Curcio, E., Almada-Lobo, B., Barbosa-Póvoa, A. P. F. D., \& Grossmann, I. E. (2016). Supplier Selection in the Processed Food Industry under Uncertainty. European Journal of Operational Research, 252(3), 801-814. http://doi.org/10.1016/j.ejor.2016.02.005

Ayhan, M. B., \& Kilic, H. S. (2015). A two stage approach for supplier selection problem in multi-item/multisupplier environment with quantity discounts. Computers and Industrial Engineering, 85, 1-12. http://doi.org/10.1016/j.cie.2015.02.026

Bruno, G., Esposito, E., Genovese, A., \& Simpson, M. (2016). Applying supplier selection methodologies in a multi-stakeholder environment: A case study and a critical assessment. Expert Systems with Applications, 43, 271-285. http://doi.org/10.1016/j.eswa.2015.07.016

Burke, G. J., Carrillo, J., \& Vakharia, A. J. (2008). Heuristics for sourcing from multiple suppliers with alternative quantity discounts. European Journal of Operational Research, 186(1), 317-329. http://doi.org/10.1016/j.ejor.2007.01.019

Büyüközkan, G., \& Çifçi, G. (2012). A novel hybrid MCDM approach based on fuzzy DEMATEL, fuzzy ANP and fuzzy TOPSIS to evaluate green suppliers. Expert Systems with Applications, 39(3), 3000-3011. http://doi.org/10.1016/j.eswa.2011.08.162

Chen, T.-Y., \& Ku, T.-C. (2008). Importance-assessing method with fuzzy number-valued fuzzy measures and discussions on TFNs and TrFNs. International Journal of Fuzzy Systems, 10(2), 92.

Chou, S., \& Chang, Y. (2008). A decision support system for supplier selection based on a strategy-aligned fuzzy SMART approach. Expert Systems with Applications, 34(4), 2241-2253. http://doi.org/10.1016/j.eswa.2007.03.001

Dahel, N.-E. (2003). Vendor selection and order quantity allocation in volume discount environments. Supply Chain Management: An International Journal, 8(4), 335-342. http://doi.org/10.1108/13598540310490099

Dehghani, M., Esmaeilian, M., \& Tavakkoli-Moghaddam, R. (2013). Employing Fuzzy ANP for Green Supplier Selection and Order Allocations: A Case Study . International Journal of Economy, Management and Social Sciences, 2(8), 565-575.

Deng, X., Hu, Y., Deng, Y., \& Mahadevan, S. (2014). Supplier selection using AHP methodology extended by D numbers. Expert Systems with Applications, 41(1), 156-167. http://doi.org/10.1016/j.eswa.2013.07.018

Dickson, G. W. (1966). An analysis of vendor selection systems and decisions. Journal of Purchasing, 2(1), 517. http://doi.org/10.5465/AMBPP.1966.4980919

Ebrahim, R. M., Razmi, J., \& Haleh, H. (2009). Scatter search algorithm for supplier selection and order lot sizing under multiple price discount environment. Advances in Engineering Software, 40(9), 766-776. 
http://doi.org/10.1016/j.advengsoft.2009.02.003

Freeman, J., \& Chen, T. (2015). Green supplier selection using an AHP-Entropy-TOPSIS framework. Supply Chain Management: An International Journal, 20(3), 327-340. http://doi.org/10.1108/SCM-04-20140142

Ghorbani, M., Bahrami, M., \& Arabzad, S. M. (2012). Implementing Shannon Entropy, SWOT and Mathematical Programming for Supplier Selection and Order Allocation. International Journal of Supply Chain Management, 1(1), 43-47. http://doi.org/10.1016/j.sbspro.2012.04.064

Hafezalkotob, A. (2015). Competition of two green and regular supply chains under environmental protection and revenue seeking policies of government. Computers and Industrial Engineering, 82, 103-114. http://doi.org/10.1016/j.cie.2015.01.016

Hamdan, S., \& Cheaitou, A. (2015). Green supplier selection and order allocation using an integrated fuzzy TOPSIS, AHP and IP approach. In The 2015 International Conference on Industrial Engineering and Operations Management. Dubai, UAE: IEEE. http://doi.org/10.1109/IEOM.2015.7093826

Hamdan, S., \& Cheaitou, A. (2017). Supplier selection and order allocation with green criteria: An MCDM and multi-objective optimization approach. Computers \& Operations Research, 81, 282-304. http://doi.org/10.1016/j.cor.2016.11.005

Hamdan, S., \& Cheaitou, A. Datasets for supplier selection and order allocation with green criteria, all-unit quantity discounts and varying number of suppliers, Data in Brief, Submitted (n.d.)

Igarashi, M., de Boer, L., \& Fet, A. M. (2013). What is required for greener supplier selection? A literature review and conceptual model development. Journal of Purchasing and Supply Management, 19(4), 247263. http://doi.org/10.1016/j.pursup.2013.06.001

Kamali, A., Fatemi Ghomi, S. M. T., \& Jolai, F. (2011). A multi-objective quantity discount and joint optimization model for coordination of a single-buyer multi-vendor supply chain. Computers \& Mathematics with Applications, 62(8), 3251-3269. http://doi.org/10.1016/j.camwa.2011.08.040

Kannan, D., Khodaverdi, R., Olfat, L., Jafarian, A., \& Diabat, A. (2013). Integrated fuzzy multi criteria decision making method and multi-objective programming approach for supplier selection and order allocation in a green supply chain. Journal of Cleaner Production, 47, 355-367. http://doi.org/10.1016/j.jclepro.2013.02.010

Karpak, B., Kumcu, E., \& Kasuganti, R. (1999). An application of visual interactive goal programming: a case in vendor selection decisions. Journal of Multicriteria Decision Analysis, 8(2), 93-105.

Kilic, H. S. (2013). An integrated approach for supplier selection in multi-item/multi-supplier environment. Applied Mathematical Modelling, 37(14-15), 7752-7763. http://doi.org/10.1016/j.apm.2013.03.010

Kokangul, A., \& Susuz, Z. (2009). Integrated analytical hierarch process and mathematical programming to supplier selection problem with quantity discount. Applied Mathematical Modelling, 33(3), 1417-1429. http://doi.org/10.1016/j.apm.2008.01.021

Kwong, C. K., Ip, W. H., \& Chan, J. W. K. (2002). Combining scoring method and fuzzy expert systems approach to supplier assessment: a case study. Integrated Manufacturing Systems, 13(7), 512-519. http://doi.org/10.1108/09576060210442671

Lau, H. C. W., Wong, C. W. Y., Lau, P. K. H., Pun, K. F., Chin, K. S., \& Jiang, B. (2003). A fuzzy multicriteria decision support procedure for enhancing information delivery in extended enterprise networks. Engineering Applications of Artificial Intelligence, 16(1), 1-9. http://doi.org/10.1016/S09521976(03)00020-4

Lee, A. H. I., Kang, H.-Y., Lai, C.-M., \& Hong, W.-Y. (2013). An integrated model for lot sizing with supplier selection and quantity discounts. Applied Mathematical Modelling, 37(7), 4733-4746. http://doi.org/10.1016/j.apm.2012.09.056

Leiserson, C. C. E., Rivest, R. R. L., Stein, C., \& Cormen, T. H. (2009). Introduction to Algorithms (3rd ed.). 
Massachusetts: The MIT Press. http://doi.org/10.2307/2583667

Lima Junior, F. R., Osiro, L., \& Carpinetti, L. C. R. (2014). A comparison between Fuzzy AHP and Fuzzy TOPSIS methods to supplier selection. Applied Soft Computing, 21, 194-209.

http://doi.org/10.1016/j.asoc.2014.03.014

Mafakheri, F., Breton, M., \& Ghoniem, A. (2011). Supplier selection-order allocation: A two-stage multiple criteria dynamic programming approach. International Journal of Production Economics, 132(1), 52-57. http://doi.org/10.1016/j.ijpe.2011.03.005

Mansini, R., Savelsbergh, M. W. P., \& Tocchella, B. (2012). The supplier selection problem with quantity discounts and truckload shipping. Omega, 40(4), 445-455. http://doi.org/10.1016/j.omega.2011.09.001

Marler, R. T., \& Arora, J. S. (2004). Survey of multi-objective optimization methods for engineering. Structural and Multidisciplinary Optimization, 26(6), 369-395. http://doi.org/10.1007/s00158-003-0368-6

Mazdeh, M. M., Emadikhiav, M., \& Parsa, I. (2015). A heuristic to solve the dynamic lot sizing problem with supplier selection and quantity discounts. Computers and Industrial Engineering, 85, 33-43. http://doi.org/10.1016/j.cie.2015.02.027

Memon, M. S., Lee, Y. H., \& Mari, S. I. (2015). Group multi-criteria supplier selection using combined grey systems theory and uncertainty theory. Expert Systems with Applications, 42(21), 7951-7959. http://doi.org/10.1016/j.eswa.2015.06.018

Moghaddam, K. S. (2015). Fuzzy multi-objective model for supplier selection and order allocation in reverse logistics systems under supply and demand uncertainty. Expert Systems with Applications, 42(15-16), 6237-6254. http://doi.org/10.1016/j.eswa.2015.02.010

Razmi, J., \& Maghool, E. (2010). Multi-item supplier selection and lot-sizing planning under multiple price discounts using augmented ??-constraint and Tchebycheff method. International Journal of Advanced Manufacturing Technology, 49(1-4), 379-392. http://doi.org/10.1007/s00170-009-2392-1

Sawik, T. (2010). Single vs. multiple objective supplier selection in a make to order environment. Omega, 38(34), 203-212. http://doi.org/10.1016/j.omega.2009.09.003

Taleizadeh, A. A., Stojkovska, I., \& Pentico, D. W. (2015). An economic order quantity model with partial backordering and incremental discount. Computers and Industrial Engineering, 82, 21-32. http://doi.org/10.1016/j.cie.2015.01.005

Wang, J.-W., Cheng, C.-H., \& Huang, K.-C. (2009). Fuzzy hierarchical TOPSIS for supplier selection. Applied Soft Computing, 9(1), 377-386. http://doi.org/10.1016/j.asoc.2008.04.014

Wang, T.-Y., \& Yang, Y.-H. (2009). A fuzzy model for supplier selection in quantity discount environments. Expert Systems with Applications, 36(10), 12179-12187. http://doi.org/10.1016/j.eswa.2009.03.018

Xia, W., \& Wu, Z. (2007). Supplier selection with multiple criteria in volume discount environments, di, 494504. http://doi.org/10.1016/j.omega.2005.09.002

Zhang, C. T., Wang, H. X., \& Ren, M. L. (2014). Research on pricing and coordination strategy of green supply chain under hybrid production mode. Computers and Industrial Engineering, 72(1), 24-31. http://doi.org/10.1016/j.cie.2014.03.012

Zhang, J., \& Chen, J. (2013). Supplier selection and procurement decisions with uncertain demand, fixed selection costs and quantity discounts. Computers \& Operations Research, 40(11), 2703-2710. http://doi.org/10.1016/j.cor.2013.05.016

Zhang, J., \& Zhang, M. (2011). Supplier selection and purchase problem with fixed cost and constrained order quantities under stochastic demand. International Journal of Production Economics, 129(1), 1-7. http://doi.org/10.1016/j.ijpe.2010.08.003 